\title{
Role of activated carbon on micropollutants degradation by different radiation processes
}

\author{
Inmaculada Velo-Gala, Jesús J. López-Peñalver*, Manuel Sánchez-Polo and José Rivera-Utrilla \\ Department of Inorganic Chemistry, Faculty of Science, Granada University, Granada, Spain
}

\begin{abstract}
This work supplements our previous studies, but in this work, we stress the ability of activated carbon by itself to stabilize the radicals formed in advanced oxidation processes. We selected four commercial activated carbon and sixteen gamma irradiated-modified carbons derived from these and triiodinated contrast medium diatrizoate (DTZ) was chosen as the contaminant model. The different advanced oxidation/reduction processes studied were improved through the addition of activated carbon in the UV light and gamma radiating processes. We studied the interaction of radicals generated by oxidizing pathway (UV/activated carbon process) and spices formed by reductive process (gamma radiation/activated carbon process) with different activated carbons. The individual study of both processes, UV/activated carbon process and gamma irradiated/activated carbon process, showed that activated carbon played a decisive role in the speed of degradation of DTZ and that activated carbon did not behave as an inert material as others authors defend. In both systems, we showed that activated carbon was capable of stabilizing the radicals generated, through their conjugate surface groups or graphene sheets, which improved the removal of the DTZ, provided that there were adsorbent-adsorbate electrostatic interactions. If there were no such interactions, or these were impeded, the synergistic effect due to the action of the activated carbon did not occur. These results suggested that activated carbon had catalytic activity under different energy sources. Based on these results, we propose that activated carbon stabilizes the radicals on its surface, increasing radicals in the medium and favouring the elimination of pollutants. This effect is independent of the textural properties but not the chemical properties of the activated carbon, observing a higher effect for carbons with a higher surface content of oxygen, specifically quinone groups. Finally, we want highlight that the effect catalytic of activated carbon requires adsorbent-adsorbate electrostatic interactions.
\end{abstract}

Keywords: UV radiation; activated carbon; band gap; photocatalysis; sodium diatrizoate; radiolysis.

Abbreviation: Advanced Oxidation/Reduction Processes (AORPs), activated carbon (AC), sodium diatrizoate (DTZ), Ceca AC-40 (C), Merck (M), Sorbo-Norit (S), Witco (W), X-ray photoelectron spectroscopy (XPS), solvated electrons $\left(e_{a q}^{-}\right)$, hydrogen radicals $\left(\mathrm{H}^{\bullet}\right)$, hydroxyl radicals $\left(\mathrm{OH}^{\bullet}\right), \mathrm{pH}$ of point of zero charge $(\mathrm{pHPZC})$, initial pH (pHinitial), final pH (pHfinal), surface area (SBET), Brunauer-Emmett-Teller (BET) model, total pore volume (VT), pore diameter (Dp), micropore volume (V0(N2)), and external surface volume (SExt), ultramicropore volume (V0 (CO2)), diffuse reflectance spectra (DRS), high performance liquid chromatography (HPLC), UV/activated carbon process (UV/AC), band gap (Eg).

\section{Introduction}

Advanced Oxidation Processes (AOPs) or Advanced Oxidation/Reduction Processes (AORPs) appear to be a promising technology for removing organic compounds that are resistant to conventional biological treatments. The activated carbon has the capacity to improve AOPs or AORPs in which is present. Adsorption on activated carbons (ACs) has been proposed as a method to remove this type of recalcitrant pollutant from effluents. The utilization of AC to eliminate organic and inorganic compounds from water is currently considered one of the best options available for the tertiary treatment of urban wastewater treatment plant effluents. AC can remove a large amount of pollutants of different types $^{1-4}$ due to the physicochemical properties of its surface $^{5}$. These properties can be modified by using different activation methods, allowing the preparation of carbons to be tailored for specific objectives ${ }^{6-9}$. This versatility in their application is widened by their combination with other physical

and chemical processes, such as AOPs, or by their application in catalysis, yielding innumerable possibilities for the treatment of all kinds of pollutants ${ }^{10-14}$. The utilization of ACs to enhance conventional treatment systems is therefore of great interest.

\footnotetext{
*Corresponding author: Jesús J. López-Peñalver

E-mail address: jipenalver@ugr.es

DOI: http://dx.doi.org/10.13171/mjc.4.2.2015.04.01.16.40/Lopez-Penalver
} 
Photocatalytic processes are well known advances oxidation processes, which require the use of luminous radiation capable of producing electronic activation of the catalyst. Various materials have been used as photocatalysts but documented drawbacks of utilizing these materials include: the difficulty of their removal from the treated effluent, the necessity to their recovery and reutilization, the reduced percentage absorption of the solar spectrum, and the high level of recombination of electron-hole pairs. Recent investigation shave centered on photocatalysis processes that reduce these disadvantages. The immobilization of these photocatalysts in porous carbon materials is a research line of special interest, as reflected by the exponential increase in the number of publications over the past few years ${ }^{15-21}$. The photocatalytic process can be improved by the physical and chemical properties of activated carbons, especially their large specific surface area, which is usually attributed to the increase in contact surface area between catalyst and pollutant, favored by the action of the carbon as porous support ${ }^{20,22-24}$. In earlier investigations, we have reported that activated carbon has photochemical activity in the absence of conventional semiconductors, improving the photooxidation of pollutant ${ }^{25}$.

On the other hand, the oxidizing pathway used to treat certain pollutants can be very slow, and the use of reducing radicals is more effective, including solvated electrons $\left(e_{a q}^{-}\right)$or hydrogen radicals $\left(\mathrm{H}^{\bullet}\right)$. Hence, the application of technologies that simultaneously generate oxidizing and reducing species, as in the case of ionizing radiations, may be of value in the treatment of pollutants resistant to conventional techniques. Thus, currently the ionzing radiation is applied to treat water contaminated with pollutants resistant to advanced oxidation processes ${ }^{26-}$ 29. However, there has been little research on the effects of the presence of catalysts, specifically AC, during the irradiation of contaminated waters. The application of AC with radiolysis may create a synergic effect that enhances the compound degradation, producing higher percentage degradation values than would be expected by adding together the effects of oxidizing radicals and reducing radicals from the radiolysis and adsorptive effect from AC. The use of AC in the presence of energy sources represents a novel procedure that could be applied in current radiolysis based effluent treatment systems and improve their effectiveness ${ }^{26-29}$ because in the same treatment contaminants can be (i) adsorbed on $\mathrm{AC}$, and/or (ii) oxidized due to the generation of hydroxyl radical $\left(\mathrm{OH}^{\bullet}\right)$ species, and/or (iii) reduced due to the formation of solvated electrons, increasing the benefit of the process.

Sodium diatrizoate has been selected as a contaminant model to evaluate the effect of the proposed processes in this study. DTZ is an iodate contrast media used in hospitals, it is highly polar, stable, and chemically inert and is eliminated unmetabolized after its administration. Thereby, this compound has been detected in urban wastewaters, surface waters, and ground waters ${ }^{30-34}$. Diatrizoate is not mineralized in the environment ${ }^{35,36}$ but can degrade, resulting in stable by-products that are potentially more harmful than the original compound $^{36-38}$. Even it was shown the high resistant from DTZ to physicochemical process as the ozonation method and ozone joint with UV lamp and hydrogen peroxide, in which DTZ degradations were $14 \%$ and $36 \%$ respectively 39,40 .

With this background, the main aims of this study were to analyze the effect of adding different ACs on the radiolytic process and to identify the origin of the photocatalytic behavior of ACs in the presence of UV light. For this purpose, we selected four commercial carbons and sixteen gamma-irradiated activated carbons derived from these ${ }^{41}$. The specific objectives were to study: (i) the adsorption kinetics of DTZ on the commercial activated carbons and the gammaradiated carbons under different experimental conditions; (ii) the DTZ degradation kinetics by direct photolysis with low-pressure UV radiation; (iii) the DTZ photodegradation in the presence of activated carbons; and (iv) the mechanism under-lying DTZ degradation with UV light in the presence of activated carbon, determining the role of the physical and chemical properties of the activated carbon in this process; (v) the kinetics of the radiolysis in the presence of different types of $\mathrm{AC}$; (vi) the mechanisms involved in DTZ removal with the combined use of $\mathrm{AC}$ and radiolysis, and (vii) the influence of the physical and chemical characteristics of the ACs on the outcomes of this combined treatment.

\section{Experimental Section \\ Reagents}

All chemical products used (sodium diatrizoate, phosphoric acid, sodium chloride, potassium bromide, sodium nitrate, sodium carbonate, acetonitrile, formic acid) were high-purity analytical grade and supplied by Sigma-Aldrich. All solutions were prepared with ultra-pure water obtained using Milli-Q® equipment (Millipore). Four commercial activated carbons were used: Ceca AC-40 (C), Merck (M), Sorbo-Norit (S), and Witco (W). Activated carbon particle had a size less than $0.25 \mathrm{~mm}$.

\section{Determination of sodium diatrizoate in aqueous solution}

DTZ concentrations in solution were determined by high performance liquid chromatography (HPLC) in inverse phase using a chromatograph (ThermoFisher) equipped with UV-vis detector and an autosampler with capacity for 120 vials. The chromatographic column was a Nova-Pak ${ }^{\circledR} \mathrm{C} 18$ (4 $\mu \mathrm{m}$ particle size; $3.9 \times 150 \mathrm{~mm})$. The mobile phase was $80 \%$ of water solution (1\% phosphoric acid) and $20 \%$ ultrapure water, in isocratic mode, with $2.0 \mathrm{~mL}$ $\mathrm{min}^{-1}$ flow; the detector wavelength was set at $254 \mathrm{~nm}$ and injection volume was $100 \mu \mathrm{L}$. 
Photolysis of sodium diatrizoate

DTZ degradation experiments using UV radiation and UV/activated carbon processes (UV/AC) were conducted in a photoreactor (inner diameter of $13 \mathrm{~cm}$ $\times$ height of $45 \mathrm{~cm}$ ) with walls of stainless steel. The photoreactor is equipped with a sample holder with a capacity for 6 quartz tubes (wall-width of $3 \mathrm{~mm}$, inner diameter of $15 \mathrm{~mm}$, height of $300-\mathrm{mm}$ ) that have a $92 \%$ transmittance for a wavelength of $254 \mathrm{~nm}$. A low-pressure mercury lamp ( $\mathrm{Hg} 253.70 \mathrm{~nm}$ ) Heraeus Noblelight, model TNN 15/32 (15 W), is placed in the center of the sample holder to ensure uniform irradiation of the six quartz tubes. The photoreactor was filled with ultrapure water that surrounded the sample holder and mercury lamp and was maintained in continuous recirculation at a constant temperature $(298.0 \pm 0.2 \mathrm{~K})$ using a Frigiterm ultra thermostat. The photoreactor was equipped with a magnetic agitation system for maintaining the solutions within the quartz tubes under constant agitation.

For the study of direct DTZ photolysis, three 25 $\mathrm{mg} \mathrm{L}^{-1} \mathrm{DTZ}$ solutions were prepared at $\mathrm{pH} 2,6.5$, and 12 , and $30 \mathrm{~mL}$ of the respective solutions were placed in the quartz tubes in the photoreactor. These solutions were maintained under constant agitation during the entire experiment at a temperature of 298 $\mathrm{K}$ and with the application of UV light at $253.70 \mathrm{~nm}$ wavelength. Samples were drawn from each solution at regular time intervals for subsequent measurement of the DTZ concentration.

\section{Diatrizoate degradation by the UV/activated carbon system}

Table 1. Designations of the activated carbon samples

\begin{tabular}{|c|c|c|}
\hline \multirow{5}{*}{ Ceca series } & $\mathrm{C}$ & Pristine activated carbon Ceca \\
\hline & $\mathrm{C}-\mathrm{H}^{\bullet}$ & Activated carbon irradiated in the presence of $\mathrm{H}^{\bullet}$ \\
\hline & $C-e_{a q}^{-}$ & Activated carbon irradiated in the presence of $\mathrm{e}_{\mathrm{aq}}^{-}$ \\
\hline & $\mathrm{C}-\mathrm{OH}^{\bullet}$ & Activated carbon irradiated in the presence of $\mathrm{OH}^{\bullet}$ \\
\hline & $\mathrm{C}-0$ & Activated carbon irradiated in the presence of all radicals \\
\hline \multirow{5}{*}{ Merck series } & $\mathrm{M}$ & Pristine activated carbon Merck \\
\hline & $\mathrm{M}-\mathrm{H}^{\bullet}$ & Activated carbon irradiated in the presence of $\mathrm{H}^{\bullet}$ \\
\hline & $\mathrm{M}-\mathrm{e}_{\mathrm{aq}}^{-}$ & Activated carbon irradiated in the presence of $\mathrm{e}_{\mathrm{aq}}^{-}$ \\
\hline & $\mathrm{M}-\mathrm{OH}^{\bullet}$ & Activated carbon irradiated in the presence of $\mathrm{OH}^{\bullet}$ \\
\hline & M-0 & Activated carbon irradiated in the presence of all radicals \\
\hline \multirow{5}{*}{ Sorbo series } & $\mathrm{S}$ & Pristine activated carbon Sorbo \\
\hline & $\mathrm{S}-\mathrm{H}^{\bullet}$ & Activated carbon irradiated in the presence of $\mathrm{H}^{\bullet}$ \\
\hline & $\mathrm{S}-\mathrm{e}_{\mathrm{aq}}^{-}$ & Activated carbon irradiated in the presence of $\mathrm{e}_{\mathrm{aq}}^{-}$ \\
\hline & $\mathrm{S}-\mathrm{OH}^{\bullet}$ & Activated carbon irradiated in the presence of $\mathrm{OH}^{\bullet}$ \\
\hline & $\mathrm{S}-0$ & Activated carbon irradiated in the presence of all radicals \\
\hline \multirow{5}{*}{ Witco series } & $\mathrm{W}$ & Pristine activated carbon Witco \\
\hline & $\mathrm{W}-\mathrm{H}^{\bullet}$ & Activated carbon irradiated in the presence of $\mathrm{H}^{\bullet}$ \\
\hline & $\mathrm{W}-\mathrm{e}_{\mathrm{aq}}^{-}$ & Activated carbon irradiated in the presence of $\mathrm{e}_{\mathrm{aq}}^{-}$ \\
\hline & $\mathrm{W}-\mathrm{OH}^{\bullet}$ & Activated carbon irradiated in the presence of $\mathrm{OH}^{\bullet}$ \\
\hline & $\mathrm{W}-0$ & Activated carbon irradiated in the presence of all radicals \\
\hline
\end{tabular}

Experimental data for DTZ photodegradation with activated carbon were obtained by the UV irradiation $(253.70 \mathrm{~nm})$ of $25 \mathrm{mg} \mathrm{L}^{-1}$ solutions of DTZ in the presence of $5 \mathrm{mg}$ activated carbon at $\mathrm{pH} 6.5$ and 298 K under constant agitation. Samples were drawn at regular time intervals to follow DTZ degradation kinetics. Samples were immediately filtered by Millipore disk filters $(0.45 \mu \mathrm{m})$ to remove the activated carbon.

\section{Gamma irradiation source}

Irradiation experiments were conducted using a JL Shepherd Mark 1 gamma irradiator (model 30J) in the Experimental Radiology Unit of the Scientific Instrumentation Center of the University of Granada (Spain). The equipment includes four $137 \mathrm{Cs}$ radioactive sources with a total combined activity of $3.70 \times 10^{13} \mathrm{~Bq}(1000 \mathrm{Ci})$. The irradiation chamber has a useful volume of $8.25 \mathrm{~L}$ and is equipped with a rotation system that guarantees uniform dose application throughout the irradiation volume. The apparatus has three irradiation positions for different dose rates: position 1, $3.83 \mathrm{~Gy} \mathrm{~min}^{-1}$; position 2, 1.66 Gy $\mathrm{min}^{-1}$; and position 3: $1.06 \mathrm{~Gy} \mathrm{~min}^{-1}$.

\section{Gamma-irradiated activated carbons}

All activated carbons used were texturally and chemically characterized as described in detail elsewhere ${ }^{41}$. ACs characteristics are given in Tables S1 (Textural characteristics) and S2 (Chemical characteristics) in the supplementary data. Table 1 shows the designation of different activated carbon used 


\section{Sodium diatrizoate degradation kinetics by radiolysis}

DTZ degradation kinetics with gamma irradiation were obtained by irradiating $1000 \mathrm{mg} \mathrm{L}^{-1}$ DTZ at 298 $\mathrm{K}$ and $\mathrm{pH} 6.5$ drawing samples at different doses (25, $50,100,200,400,600 \mathrm{~Gy}$ ) and the DTZ concentration was determined for these doses. The dose rate was $1.66 \mathrm{~Gy} \mathrm{~min}^{-1}$.

DTZ samples were irradiated at room temperature $(298 \pm 2 \mathrm{~K})$ in $2 \mathrm{~mL}$ vials sealed with screw tops to avoid the entry of air. Before the irradiation, nitrogen was bubbled through the samples to avoid the presence of dissolved oxygen in the medium.

\section{Sodium diatrizoate radiolysis in the presence of activated carbon}

The experimental conditions for DTZ radiolysis in the presence of $\mathrm{AC}$ were the same as those for the adsorption and radiolysis experiments in the absence of AC, irradiating $1000 \mathrm{mg} \mathrm{L}^{-1} \mathrm{DTZ}$ at $298 \mathrm{~K}$ and $\mathrm{pH}$ 6.5 , in the presence of $0.06 \mathrm{~g} \mathrm{AC}$ and drawing samples after different doses $(25,50,100,200,400$, and 600 Gy). All samples were immediately filtered (Millipore filters, $0.45 \mu \mathrm{m}$ ) to remove the AC before determining DTZ concentration of each sample.

\section{Study of the radicals responsible for sodium diatrizoate degradation during radiolysis}

Gamma irradiation breaks the water molecule, forming various highly reactive radical species, both oxidizing $\left(\mathrm{OH}^{\bullet}\right)$ and reducing $\left(\mathrm{H}^{\bullet}, e_{a q}^{-}\right)$. The influence of these radicals generated in radiolysis on DTZ degradation was studied by irradiating $1000 \mathrm{mg}$ $\mathrm{L}^{-1}$ DTZ solutions in the presence of $0.06 \mathrm{~g} \mathrm{AC}$, using carbons $\mathrm{S}$ and $\mathrm{C}$ as models. For this purpose, we added the corresponding salts $\left(\mathrm{NaCl}, \mathrm{KBr}, \mathrm{NaNO}_{3}\right)$ to reach concentrations in the reaction medium of 1000 $\mathrm{mg} \mathrm{L}^{-1}$ of: (i) $\mathrm{Cl}^{-}$anion at $\mathrm{pH}=1.0$, when $\mathrm{H}^{\bullet}$ is the predominant radical species in the medium because this anion acts as $\mathrm{OH}^{\bullet}$ radical scavenger (Reaction 29), and at $\mathrm{pH} 1.0$, when the reaction of $e_{a q}^{-}$with $\mathrm{H}^{+}$is favored (Reaction 10) ${ }^{42,43}$; (ii) anion $\mathrm{Br}^{-}$at $\mathrm{pH}=7.5$, with this ion acting as $\mathrm{HO}^{\bullet}$ radical scavenger (Reactions 11-14) (4-46 $^{2}$ and the $\mathrm{pH}$ favoring the reaction of $\mathrm{H}^{\bullet}$ radicals with the hydroxyl anions present (Reaction 15), resulting in the predominance of solvated electrons in the medium; and (iii) anion $\mathrm{NO}_{3}{ }^{-}$at $\mathrm{pH}=12.5$, when the $\mathrm{OH}^{\circ}$ radical is the predominant species in the medium, because the $\mathrm{NO}_{3}$ anion acts as $\mathrm{H}^{\bullet}$ and $e_{a q}^{-}$scavenger (Reactions 16 , $17)^{43,46,47}$. All samples were bubbled with nitrogen to prevent the presence of dissolved oxygen, and the vials were sealed to prevent the entry of air.

The influence of the presence of the above anions on DTZ irradiation in the absence of ACs and on DTZ adsorption on activated carbons was assessed by preparing samples under the same conditions as for the radiolysis in the presence of AC. Samples were again drawn at the times corresponding to the doses of $25,50,100,200,400$, and $600 \mathrm{~Gy}$, and all samples containing $\mathrm{AC}$ were immediately filtered (Millipore filter, $0.45 \mu \mathrm{m})$. The DTZ concentration of all these samples were determined.

\section{Sodium diatrizoate adsorption kinetics on activated carbons}

For comparison with experiments in which gamma radiation is applied, the experimental data of DTZ adsorption on the ACs were obtained by placing $0.06 \mathrm{~g}$ of $\mathrm{AC}$ in contact with $5 \mathrm{~mL}$ of $1000 \mathrm{mg} \mathrm{L}^{-1}$ DTZ solution at $298 \mathrm{~K}$ and $\mathrm{pH}$ 6.5. DTZ adsorption on the different ACs was determined by conducting adsorption experiments under the same conditions as those for the irradiations. The total experimentation time corresponded to the total dose applied in radiolysis experiments at $600 \mathrm{~Gy}$, i.e., $361.44 \mathrm{~min}$. During this period of time, seven samples were drawn for subsequent measurement of DTZ concentration, corresponding to doses of $25 \mathrm{~Gy}$ (15.06 min), $50 \mathrm{~Gy}$ (30.12 min), $100 \mathrm{~Gy}(60.24 \mathrm{~min}), 200 \mathrm{~Gy}$ (120.48 $\mathrm{min}), 400 \mathrm{~Gy}$ (240.96 min), and $600 \mathrm{~Gy}$ (361.44 min). The samples were immediately filtered with Millipore filters $(0.45 \mu \mathrm{m})$ to remove the AC present.

On the other hand, in the case of experiments with UV radiation, the experimental data for DTZ adsorption kinetics on activated carbons were obtained by placing $5 \mathrm{mg}$ of activated carbon in contact with $30 \mathrm{~mL}$ of $25 \mathrm{mg} \mathrm{L}^{-1}$ DTZ solution at 298 $\mathrm{K}$ and $\mathrm{pH}$ 6.5. Samples were drawn at regular time intervals to determine the DTZ concentration for calculation of the amount adsorbed. The experimentation conditions for the adsorption process were the same as for UV degradation in the presence of activated carbon.

\section{Results and Discussion \\ Diatrizoate degradation with UV light in the presence of activated carbon}

We investigated the degradation of DTZ when activated carbon was present during the photolytic process (UV/AC). Figure 1 depicts DTZ removal by $\mathrm{UV}$ radiation and by the simultaneous use of UV radiation and activated carbons $\mathrm{C}, \mathrm{S}, \mathrm{M}$, or W. It is observed that the removal rate is markedly increased by the presence of activated carbon.

Based on the degradation kinetics obtained, we calculated the values of the reaction rate constants in Table 2. The values of these constants confirm the increase in reaction rate observed in the degradation kinetics. This may be attributable to the contribution to the overall removal process of DTZ adsorption on the activated carbons. For this reason, we obtained the DTZ adsorption kinetics on all of the activated carbon samples. The results in Table 2 show that carbons on $\mathrm{W}$ series have the lowest adsorptive contribution to the global removal process, but these activated carbons produce the greatest increase in DTZ removal by the UV/AC system. 


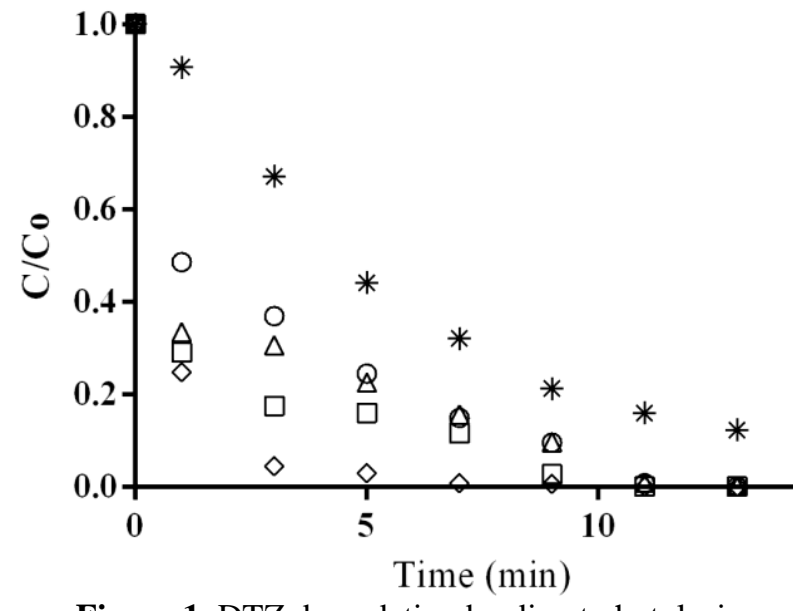

Figure 1. DTZ degradation by direct photolysis (*) and by the UV/AC system with activated carbons $\mathrm{C}(\mathrm{O}), \mathrm{M}(\triangle), \mathrm{S}(\square)$, or $\mathrm{W}(\diamond)$. $[\mathrm{DTZ}]_{0}=25 \mathrm{mg} \mathrm{L}^{-1} ; \mathrm{pH}=6.5 ; \mathrm{T}=298 \mathrm{~K}$.

These results indicate that DTZ adsorption on activated carbon is not the sole cause for the increase in DTZ removal in the UV/AC system and that the activated carbon must make other types of contribution to the overall removal process.

The role of activated carbon in DTZ removal process by UV/AC was further explored by determining the percentage removal (designated "synergic effect") of the carbons, which was calculated by subtracting the adsorptive and photolytic contributions from the global removal percentage in the UV/AC system (Eq. (1)). Results are listed in Table 2.

$\% \mathrm{~S}_{\mathrm{UV} / \mathrm{AC}}=\% \mathrm{D}_{\mathrm{UV} / \mathrm{AC}}-\% \mathrm{D}_{\mathrm{UV}}-\% \mathrm{~A}_{\mathrm{AC}}$

where $\% \mathrm{~S}_{\mathrm{UV} / \mathrm{AC}}$ is the percentage DTZ removal due to the synergic effect produced by the presence of activated carbon during exposure to UV radiation, $\% \mathrm{D}_{\text {UV/AC }}$ is the total percentage DTZ removal in the photocatalytic process UV/AC, $\% \mathrm{D}_{\mathrm{UV}}$ is the percentage DTZ degradation by direct photolysis, and $\% \mathrm{~A}_{\mathrm{AC}}$ is the percentage $\mathrm{DTZ}$ removal by adsorption on the activated carbon.

Among the different commercial activated carbons used, the results in Table 2 show that carbon $\mathrm{S}$ made the highest adsorptive contribution to the global removal process and carbon $\mathrm{W}$ the lowest. However, we highlight that carbon $\mathrm{W}$ exerts the greatest synergic effect on DTZ removal by the UV/AC system, with a synergic contribution of $>53 \%$ after the first minute of treatment.

Table 2. Removal fractions and reaction rate constants for DTZ removal by UV/AC. [DTZ $]_{0}=25 \mathrm{mg} \mathrm{L}^{-1}$; $\mathrm{pH}=6.5 ; \mathrm{T}=298 \mathrm{~K}$.

\begin{tabular}{|c|c|c|c|c|c|c|}
\hline $\begin{array}{l}\text { Exp. } \\
\text { Num. }\end{array}$ & $\begin{array}{c}\text { Activated } \\
\text { carbon }\end{array}$ & $\begin{array}{c}\mathbf{K}_{\mathbf{O B}}(\mathbf{1 5} \mathbf{~ m i n}) \\
\left(\min ^{-1}\right)\end{array}$ & $\begin{array}{c}\% \mathrm{UV} \\
\text { degradation } \\
(1 \mathrm{~min})\end{array}$ & $\begin{array}{c}\text { \% Removal by } \\
\text { adsorption } \\
(1 \mathrm{~min})\end{array}$ & $\begin{array}{c}\text { \% Removal by } \\
\text { UV/AC } \\
(1 \mathrm{~min})\end{array}$ & $\begin{array}{c}\text { \% Synergic } \\
\text { removal } \\
(1 \mathrm{~min})\end{array}$ \\
\hline 1 & $\mathrm{C}$ & $0.47 \pm 0.01$ & 9.29 & 14.20 & 51.50 & 28.01 \\
\hline 2 & $\mathrm{C}-\mathrm{H}^{\bullet}$ & $0.75 \pm 0.04$ & 9.29 & 11.70 & 49.79 & 28.80 \\
\hline 3 & $C-e_{a q}{ }^{-}$ & $0.69 \pm 0.03$ & 9.29 & 11.60 & 44.61 & 23.72 \\
\hline 4 & $\mathrm{C}-\mathrm{OH}^{\bullet}$ & $1.05 \pm 0.05$ & 9.29 & 17.00 & 53.99 & 27.70 \\
\hline 5 & $\mathrm{C}-0$ & $2.05 \pm 0.00$ & 9.29 & 12.90 & 87.09 & 64.90 \\
\hline 6 & $\mathrm{M}$ & $0.53 \pm 0.04$ & 9.29 & 18.70 & 66.60 & 38.61 \\
\hline 7 & $\mathrm{M}-\mathrm{H}^{\bullet}$ & $1.06 \pm 0.02$ & 9.29 & 30.40 & 65.38 & 25.69 \\
\hline 8 & M- $\mathrm{e}_{\mathrm{aq}}^{-}$ & $1.05 \pm 0.04$ & 9.29 & 0.86 & 65.04 & 54.89 \\
\hline 9 & $\mathrm{M}-\mathrm{OH}^{\bullet}$ & $0.93 \pm 0.05$ & 9.29 & 17.00 & 62.36 & 36.07 \\
\hline 10 & M-0 & $0.69 \pm 0.04$ & 9.29 & 12.40 & 53.05 & 31.36 \\
\hline 11 & $\mathrm{~S}$ & $0.59 \pm 0.03$ & 9.29 & 28.80 & 71.00 & 32.91 \\
\hline 12 & $\mathrm{~S}-\mathrm{H}^{\bullet}$ & $0.42 \pm 0.05$ & 9.29 & 8.49 & 45.00 & 27.22 \\
\hline 13 & S- $\mathrm{eaq}^{-}$ & $0.28 \pm 0.02$ & 9.29 & 9.07 & 32.49 & 14.13 \\
\hline 14 & $\mathrm{~S}-\mathrm{OH}^{\bullet}$ & $1.03 \pm 0.04$ & 9.29 & 14.80 & 64.10 & 39.91 \\
\hline 15 & S-0 & $1.07 \pm 0.02$ & 9.29 & 7.67 & 47.00 & 30.04 \\
\hline 16 & $\mathrm{~W}$ & $1.42 \pm 0.04$ & 9.29 & 12.80 & 75.20 & 53.11 \\
\hline 17 & $\mathrm{~W}-\mathrm{H}^{\bullet}$ & $1.02 \pm 0.04$ & 9.29 & 1.04 & 69.47 & 59.14 \\
\hline 18 & $\mathrm{~W}-\mathrm{e}_{\mathrm{aq}}^{-}$ & $5.06 \pm 0.06$ & 9.29 & 1.02 & 100 & 89.69 \\
\hline 19 & $\mathrm{~W}-\mathrm{OH}^{\bullet}$ & $5.26 \pm 0.06$ & 9.29 & 1.67 & 92.81 & 81.85 \\
\hline 20 & $\mathrm{~W}-0$ & $0.99 \pm 0.01$ & 9.29 & 8.23 & 62.87 & 45.35 \\
\hline
\end{tabular}

Figure 2 depicts the time course of the synergic contribution to the overall DTZ removal by the UV/AC system for the four original activated carbons. The results obtained indicate that, regardless of the activated carbon used, the synergic contribution decreases with longer treatment time 

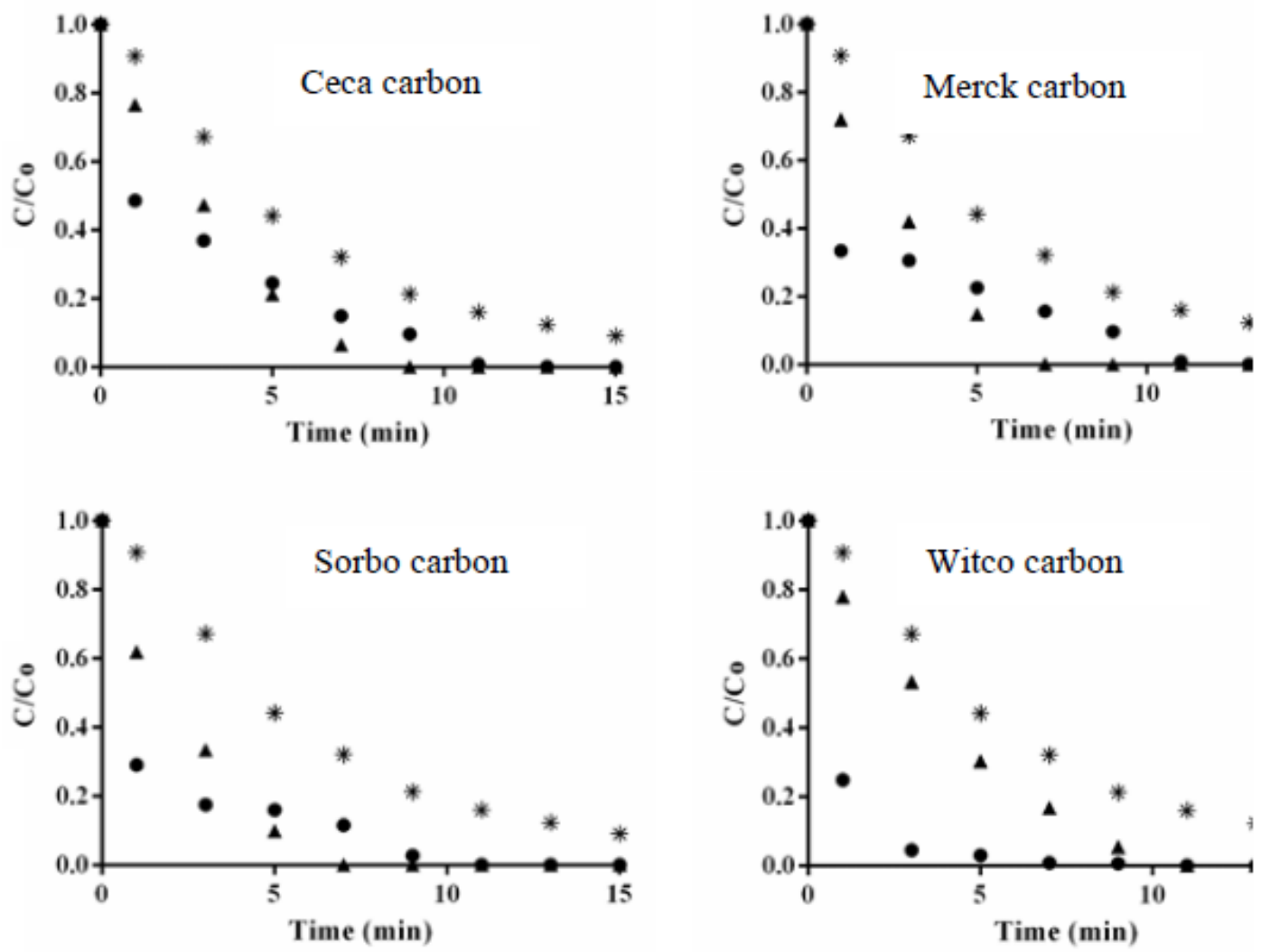

Figure 2. DTZ removal by the UV/AC system. (*), Direct photolysis; ( ), UV/AC;

(A), $\mathrm{V}+$ adsorption. [DTZ $]_{0}=25 \mathrm{mg} \mathrm{L}^{-1} ; \mathrm{pH}=6.5 ; \mathrm{T}=298 \mathrm{~K}$.

The influence of the surface chemistry of activated carbon on DTZ degradation by the UV/AC system was studied using carbons that had undergone different gamma irradiation treatments. These treatments modified the surface chemistry of the carbons (Tables S2 - S5 in supplementary data) but not their textural characteristics (Table S1, in supplementary data). Thus, we obtained carbons treated with reducing agents (solvated electrons, $e_{a q}^{-}$, and hydrogen atoms, $\mathrm{H}^{\circ}$ ) and carbons treated with oxidizing agents $\left(\mathrm{OH}^{\bullet}\right.$ radicals). The nomenclature of the resulting carbons and their chemical and textural characteristics are given in Table 1 and Tables S1 - S5 (supplementary data).

Figure 3 depicts the time course of the relative DTZ concentration during UV/AC treatment of the four series of activated carbons. We shall first discuss the results of carbon W (Fig. 3D), the activated carbon showing the greatest synergic activity. According to the results, the carbons producing the greatest increase in DTZ removal are $\mathrm{W}-e_{a q}^{-}$and $\mathrm{W}-\mathrm{OH}^{\circ}$. These results appear to indicate that, regardless of the treatment applied (oxidizing or reducing agents) irradiation of the activated carbon increases its synergic activity. The chemical properties of the treated carbons ${ }^{41}$ (Tables S2 - S5, in supplementary data) show that both treatments increase the percentage of $\mathrm{Ph}-\mathrm{OH}, \mathrm{C}-\mathrm{O}$ (ester/anhydride) groups in comparison to the original carbon. The textural and chemical properties of the activated carbons used show no clear relationship with their synergic contribution. However, the synergic activity of the activated carbon is more greatly enhanced by the samples with higher percentages of surface oxygen and, among these, the samples with higher percentages of carbon atoms with $\mathrm{sp}^{2}$ hybridization. 

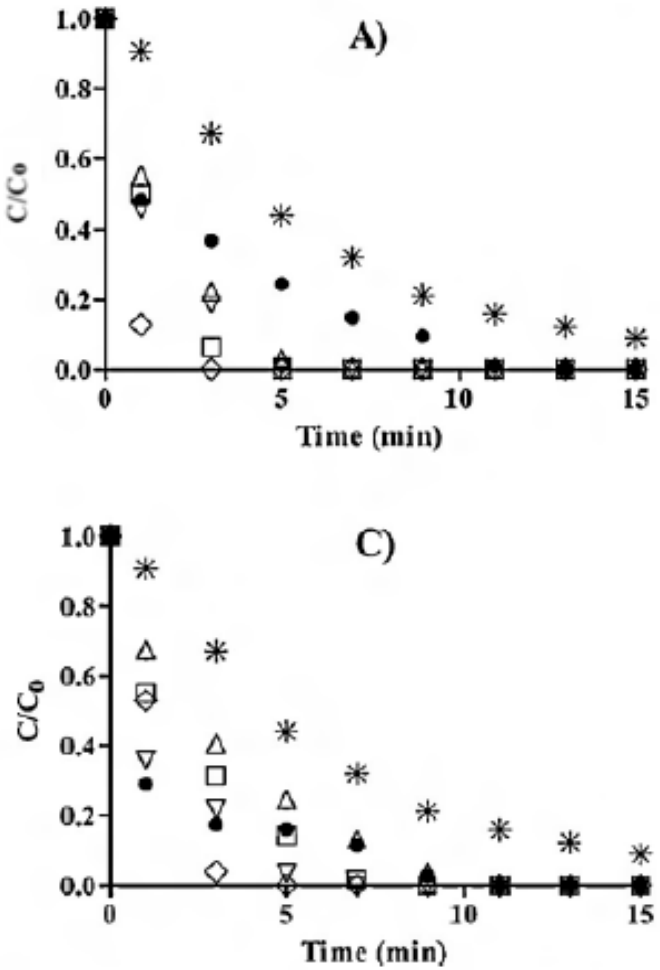
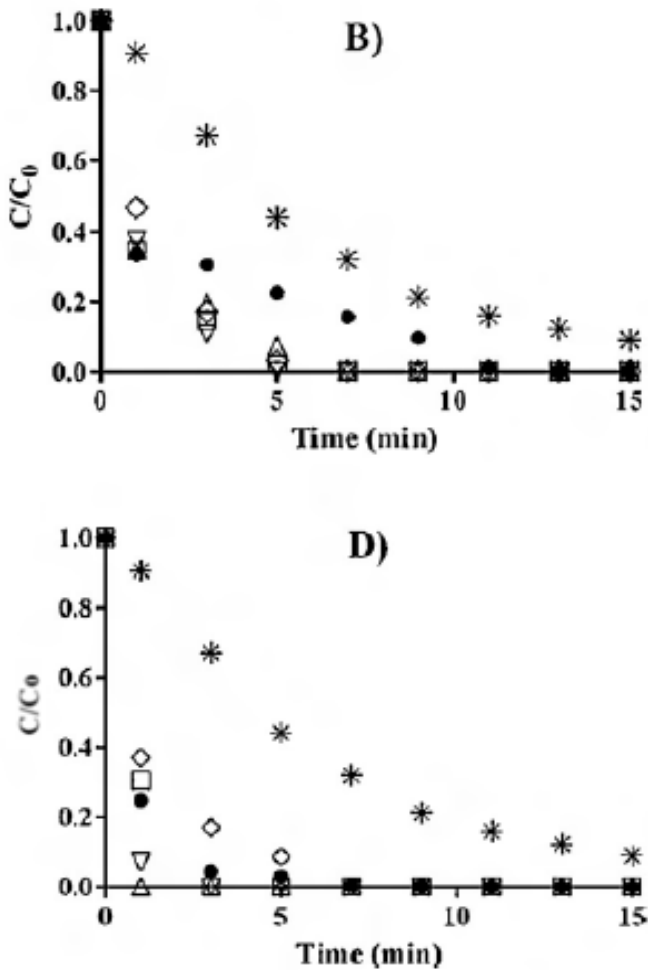

Figure 3. Time course of DTZ degradation fraction with the UV/AC system. (*), Direct photolysis; (O), UV/AC; ( $\square$ ), UV/AC-H•; $(\triangle), \mathrm{UV} / \mathrm{AC}-e_{a q}^{-} ;(\nabla), \mathrm{UV} / \mathrm{AC}-\mathrm{OH}{ }^{\bullet} ;(\diamond), \mathrm{UV} / \mathrm{CA}-0$. (A) Carbon C; (B) Carbon $\mathrm{M}$; (C) Carbon S; (D) Carbon W. [DTZ $]_{0}=25 \mathrm{mg} \mathrm{L}^{-1} ; \mathrm{pH}=6.5 ; \mathrm{T}=298 \mathrm{~K}$.

In order to dig deep into the activated carbon characteristics affecting its photocatalytic activity, we have determined the band gap (Eg) of the activated carbons ${ }^{41}$. Determination of the activated carbon band gap demonstrated that these materials behave as semiconductor materials and therefore as photoactive materials in the presence of UV light, because all Eg values are $<4 \mathrm{eV}$ (Table 3). In general, the gamma radiation treatment reduces the band gap energy of the materials and, within the same series of activated carbons, lower Eg values correspond to higher DTZ degradation values

Table 3. Band gap values (Eg) of the activated carbons, calculated according to the Kubelka-Munk method.

\begin{tabular}{|c|c|c|c|c|}
\hline Processing & $\begin{array}{c}\text { Serie C } \\
\mathbf{E}_{\mathrm{g}} \pm \mathbf{S D}(\mathrm{eV})\end{array}$ & $\begin{array}{c}\text { Serie M } \\
\mathbf{E}_{\mathrm{g}} \pm \mathbf{S D}(\mathrm{eV})\end{array}$ & $\begin{array}{c}\text { Serie } \mathbf{S} \\
\mathbf{E}_{\mathrm{g}} \pm \mathbf{S D}(\mathrm{eV})\end{array}$ & $\begin{array}{c}\text { Serie W } \\
\mathbf{E}_{\mathrm{g}} \pm \mathbf{S D}(\mathrm{eV})\end{array}$ \\
\hline$\overline{\mathbf{A C}^{\mathbf{a})}}$ & $3.65 \pm 0.06$ & $3.50 \pm 0.04$ & $3.58 \pm 0.04$ & $3.68 \pm 0.04$ \\
\hline AC-0 b) & $3.04 \pm 0.04$ & $3.33 \pm 0.04$ & $2.98 \pm 0.04$ & $3.23 \pm 0.04$ \\
\hline $\left.\mathrm{AC}-\mathrm{H}^{\bullet} \mathrm{c}\right)$ & $3.36 \pm 0.04$ & $3.13 \pm 0.04$ & $3.63 \pm 0.04$ & $3.35 \pm 0.04$ \\
\hline$\left.A C-e_{a q}^{-} d\right)$ & $3.14 \pm 0.04$ & $3.20 \pm 0.04$ & $3.16 \pm 0.04$ & $3.15 \pm 0.04$ \\
\hline $\left.\mathrm{AC}-\mathrm{OH}^{\bullet} \mathrm{e}\right)$ & $3.00 \pm 0.04$ & $3.23 \pm 0.04$ & $2.92 \pm 0.04$ & $3.10 \pm 0.04$ \\
\hline
\end{tabular}

${ }^{\text {a) }} \mathrm{AC}$ pristine; ${ }^{\mathrm{b})} \mathrm{AC}$ irradiated in ultrapure water; ${ }^{\mathrm{c})} \mathrm{AC}$ irradiated in ultrapure water, $\mathrm{pH}=1.0 \mathrm{y}\left[\mathrm{Cl}^{-}\right]=1000 \mathrm{mg} \mathrm{L}^{-1}$; ${ }^{\mathrm{d}} \mathrm{AC}$ irradiated ultrapure water, $\mathrm{pH}=7.5 \mathrm{y}\left[\mathrm{Br}^{-}\right]=1000 \mathrm{mg} \mathrm{L}^{-1} ;{ }^{\mathrm{e})} \mathrm{AC}$ irradiated in ultrapure water, $\mathrm{pH}=12.5 \mathrm{y}\left[\mathrm{NO}_{3}^{-}\right]=1000 \mathrm{mg} \mathrm{L}^{-1}$.

Our results showed that there was a positive correlation between the $\mathrm{sp}^{3} / \mathrm{sp}^{2}$ ratio and the Eg value $(\mathrm{P}<0.05, \mathrm{r}=0.4823$, Table S6 in supplementary data), revealing that an increase in $\mathrm{sp}^{2}$ hybridization was associated with a decrease in Eg value, because a larger fraction of $\mathrm{sp}^{2} \mathrm{C}$ atoms increases extensive $\pi$ conjugation and reduces band gap ${ }^{48}$.

The ultraviolet radiation absorption in carbon materials is caused by electronic transitions between the bonding and antibonding $\pi$ orbitals, since the $\pi-\pi^{*}$ transitions are located in the range between 180 and
$260 \mathrm{~nm}$. On the other hand, structural changes are correlated with a different optical behavior of these materials. Thus, the greater the content of $\mathrm{sp}^{2}$ hybridized carbon the greater is the UV peak position in wavelength and therefore the photocatalytic activity of the carbon is favored.

When an incident photon has energy greater than the band gap it is absorbed and created an electronhole pair. The photogenerated electrons would spread throughout the graphene layers and reach molecules of the absorbed pollutants and/or oxygen molecules. 
The electrons would reduce the adsorbed $\mathrm{O}_{2}$ to form superoxide radicals $\left(\mathrm{O}_{2}{ }^{\bullet-}\right)$, which can react with the water molecule and trigger the formation of oxidizing radical species (Reactions 2-4) that will interact with the contaminants, contributing to its degradation ${ }^{49}$.

$$
\begin{aligned}
& \mathrm{e}_{\mathrm{CB}}^{-}+\mathrm{O}_{2} \rightarrow \mathrm{O}_{2}^{\bullet-} \\
& \mathrm{O}_{2}^{\bullet-}+\mathrm{H}_{2} \mathrm{O} \rightarrow \mathrm{HO}_{2}^{\bullet}+\mathrm{HO}^{-} \\
& 2 \mathrm{HO}_{2}^{\bullet} \rightarrow \mathrm{O}_{2}+\mathrm{H}_{2} \mathrm{O}_{2} \rightarrow \mathrm{O}_{2}+2 \mathrm{OH}^{\bullet}
\end{aligned}
$$

The positive holes are directly responsible for the generation of hydroxyl radicals by interaction with water molecules (Reaction 5).

$$
\mathrm{h}_{\mathrm{BV}}^{+}+\mathrm{H}_{2} \mathrm{O} \rightarrow \mathrm{OH}^{\bullet}+\mathrm{H}^{+}
$$

Based on these backgrounds, we propose that the photons from UV light would fall on the activated carbons and generate electron-hole pairs through their irradiation with a sufficient amount of energy to promote electrons from the valence band to the conduction band. The photogenerated electrons would spread throughout the graphene layers and reach molecules of the absorbed DTZ and oxygen molecules. The electrons reduce the adsorbed $\mathrm{O}_{2}$ to form superoxide radicals $\left(\mathrm{O}_{2}{ }^{\bullet-}\right)$, which can react with the water molecule and trigger the formation of oxidizing radical species ${ }^{49}$ that will interact with the pollutants, contributing to its degradation. Additionally, the presence of adsorbed oxygen avoids recombination of the electron with the positive hole (Reactions 2-4), allowing interaction between the water molecule and the free hole and increasing the effectiveness of the photocatalytic process. The positive holes are directly responsible for the generation of hydroxyl radicals by interaction with

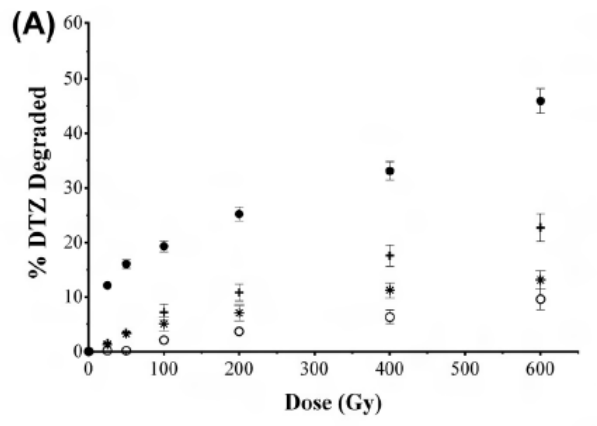

$\mathrm{OH}^{-}$groups of the carbon surface and by capture of water molecules. All this would explain the DTZ photodegradation would be encouraged in the presence of activated carbon.

Finally, we decided to study the role of activated carbon in the stabilization of the radicals formed, and for that we irradiated DTZ samples in the presence of activated carbon.

Diatrizoate degradation by gamma radiation in the presence of activated carbon

DTZ radiolysis in the presence of $\mathrm{AC}^{(4)}$ is a complex process. The degradation of DTZ by the radical species generated through the interaction of gamma radiation with the water molecule is simultaneous with the adsorption of DTZ on the AC in the medium. The influences of DTZ adsorption and radiolysis was quantified by obtaining the adsorption and radiolysis kinetics separately under the same experimental conditions as those used to obtain DTZ degradation kinetics in the presence of AC.

Figure 4 depicts the removal kinetics obtained when using the carbons, showing that the final percentage DTZ removal at a dose of $600 \mathrm{~Gy}$ is much higher in the presence of the ACs than in their absence. The difference between the effect of radiolysis in the presence of $\mathrm{AC}$ and the sum of the effects of DTZ radiolysis without AC and adsorption was more marked in the case of carbons $\mathrm{C}$ and $\mathrm{M}$. The synergic effect was lower when the DTZ adsorption rate was higher, as in the case of carbon $S$.

However, account must be taken of the adsorption of DTZ on the AC to assess whether the improvement observed is merely the sum of the effects of AC adsorption and gamma radiation or whether the presence of $\mathrm{AC}$ enhances the degradation, revealing a synergic effect of their combined use.
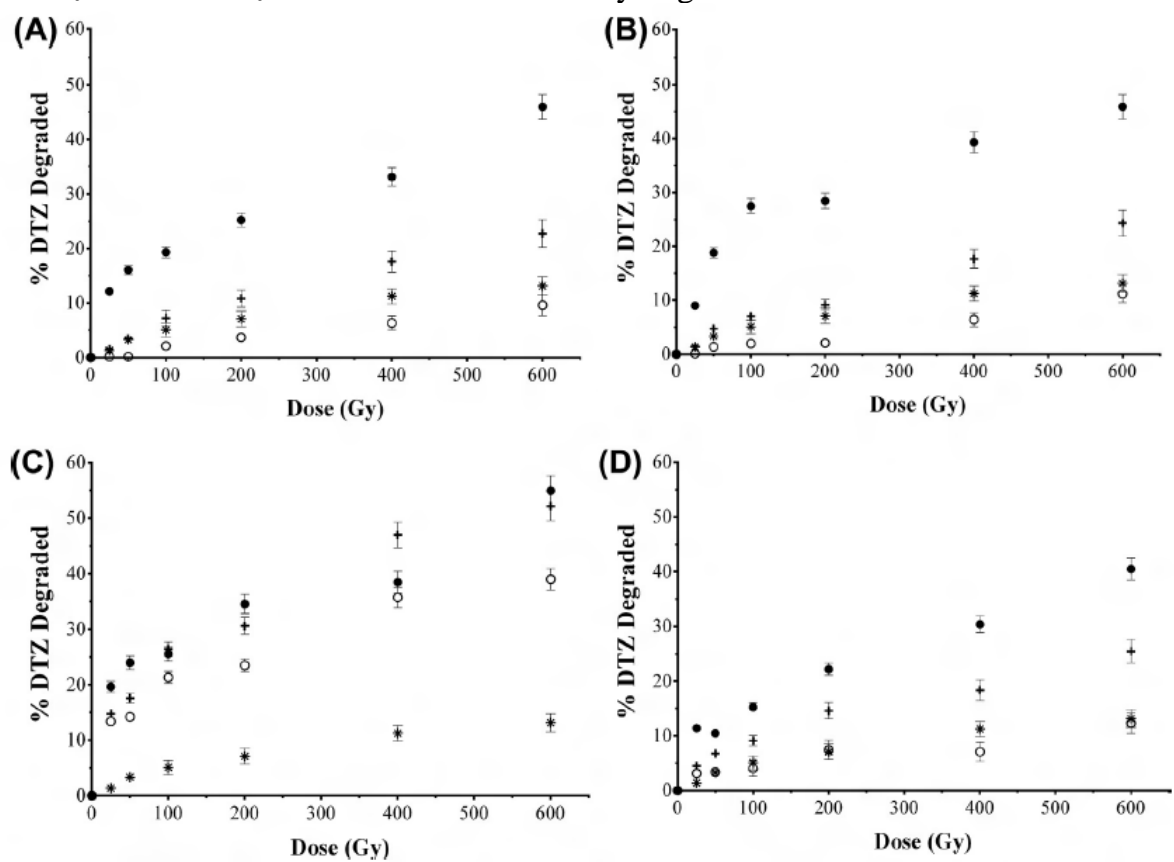

Figure 4. Percentage DTZ removal with four systems: $(*)$ radiolysis without AC; $(\bigcirc)$ radiolysis in the presence of AC; (O) DTZ adsorption on AC; and (+) theoretical sum effect of adsorption plus radiolysis. 
(A), Carbon $\mathrm{C}$ series; (B), carbon $\mathrm{M}$ series; (C), carbon $\mathrm{S}$ series; (D), carbon $\mathrm{W}$ series. [DTZ $]=1000 \mathrm{mg}$ $\mathrm{L}^{-1}$. Amount of $\mathrm{AC}=0.06 \mathrm{~g}$. $\mathrm{T}=298 \mathrm{~K}$. $\mathrm{pH}=6.5$. Dose Rate=1.66 $\mathrm{Gy} \mathrm{min}^{-1}$.

radiation with matter in the case of $\mathrm{ACs}^{50}$. The main interaction mechanism in the Compton effect is ionization, by which incident photons can interact

Comparison of the results (Figure 4) with the chemical and textural characteristics of the ACs (Tables S1 - S5 in supplementary data) showed that the synergic effect was not influenced by their textural characteristics. Therefore, the ability of the ACs to enhance radiolytic DTZ degradation by the use of gamma radiation may be related to their chemical properties. In order to understand this behavior, it should be taken into account that the gamma radiation interacts with both the AC and the water molecule. Given that carbon has a low atomic number and the radiation has an energy of $0.6617 \mathrm{MeV}$, the Compton effect would be predominant interaction of gamma

$$
\begin{aligned}
& \mathrm{O}_{2}^{\bullet-}+\mathrm{H}_{3} \mathrm{O}^{+} \rightarrow \mathrm{OH}^{\bullet}+\mathrm{H}_{2} \mathrm{O}+1 / 2 \mathrm{O}_{2} \\
& \mathrm{H}^{+}+\mathrm{O}_{2}^{--} \leftrightarrows \mathrm{HO}_{2}^{\bullet} \\
& \mathrm{HO}_{2}^{\bullet}+\mathrm{O}_{2}^{\bullet-} \rightarrow \mathrm{HO}_{2}^{-}+\mathrm{O}_{2} \\
& \mathrm{HO}_{2}^{\bullet}+\mathrm{HO}_{2}^{\bullet} \rightarrow \mathrm{H}_{2} \mathrm{O}_{2}+\mathrm{O}_{2}
\end{aligned}
$$

All of the above would contribute to increasing DTZ degradation by favoring new oxidizing species in the medium. In addition, incident gamma radiation interacts with the water molecule, giving rise to the processes described in Reactions 10-14 ${ }^{53,54}$

$$
\begin{aligned}
& \mathrm{H}_{2} \mathrm{O} \stackrel{\text { Radiation } \gamma}{\longrightarrow} \mathrm{H}_{2} \mathrm{O}^{\bullet+}+\mathrm{e}^{-} \\
& \mathrm{H}_{2} \mathrm{O} \stackrel{\text { Radiation } \gamma}{\longrightarrow} \mathrm{H}_{2} \mathrm{O}^{*}
\end{aligned}
$$

$$
\begin{aligned}
& \mathrm{OH}^{\bullet}+\mathrm{H}^{\bullet} \rightarrow \mathrm{H}_{2} \mathrm{O} \\
& \mathrm{H}^{\bullet}+\mathrm{H}^{\bullet} \rightarrow \mathrm{H}_{2} \\
& \mathrm{e}_{\mathrm{aq}}^{-}+\mathrm{H}^{\bullet}+\mathrm{H}_{2} \mathrm{O} \rightarrow \mathrm{H}_{2}+\mathrm{HO}^{-} \\
& \mathrm{OH}^{\bullet}+\mathrm{e}_{\mathrm{aq}}^{-} \rightarrow \mathrm{HO}^{-}
\end{aligned}
$$

Voudrias et al. ${ }^{55}$ used electron spin resonance to demonstrate that oxygenated groups on the $\mathrm{AC}$, especially quinone groups, can stabilize radicals on its surface, as well as the conjugated aromatic rings system. It is possible that interaction between the radicals formed during radiolysis and the carbon surface gives rise to areas with high reactivity, due to radicals stabilized by the quinone groups on the AC surface. This mechanism would be more influential with greater quinone content, explaining why the best results were obtained with carbon $S$ (Figure 4C).

The influence of each species formed during water radiolysis was analysed to explore further the mechanisms underlying the synergic activity of AC in DTZ degradation, conducting experiments in which one of the three radiolysis-induced species $\left(\mathrm{OH}^{\circ}, \mathrm{H}^{\bullet}\right.$, or $\mathrm{e}^{-}$aq $)$was predominant. Table 4 exhibits the data for DTZ radiolysis in the absence and presence of AC and in the presence of scavengers and shows the adsorption and radiolysis degradation values in the with the orbital electrons of surface atoms and produce positive ions and free electrons. Hence, the carbon atoms on the surface would contribute to increasing the free electrons in the medium, favoring DTZ degradation (reduction pathway), which would explain the synergic effect observed for the four ACs. Moreover, as reported by Boehm ${ }^{49}$, the chemisorbed oxygen on the four carbons (Table S1, supplementary data) can scavenge electrons and give rise to the formation of the superoxide anion. This anion can directly interact with DTZ, form radicals by Reaction 6 , or establish the balance of Reaction 7 to yield Reactions 8 and 9, forming $\mathrm{H}_{2} \mathrm{O}_{2}{ }^{51,52}$.

$$
\begin{aligned}
& \mathrm{k}=4.5 \times 10^{10} \mathrm{M}^{-1} \mathrm{~s}^{-1} \\
& \mathrm{k}_{\mathrm{eq}}=1.5 \times 10^{-5} \mathrm{M}^{-1} \mathrm{~s}^{-1} \\
& \mathrm{k}=8.9 \times 10^{7} \mathrm{M}^{-1} \mathrm{~s}^{-1} \\
& \mathrm{k}=2.0 \times 10^{6} \mathrm{M}^{-1} \mathrm{~s}^{-1} \\
& \mathrm{H}_{2} \mathrm{O}^{\bullet+} \rightarrow \mathrm{OH}^{\bullet}+\mathrm{H}^{+} \\
& \mathrm{e}^{-}+\mathrm{nH}_{2} \mathrm{O} \rightarrow \mathrm{e}_{\mathrm{aq}}^{-} \\
& \mathrm{H}_{2} \mathrm{O}^{*} \rightarrow \mathrm{OH}^{\bullet}+\mathrm{H}^{\bullet}
\end{aligned}
$$

Radiolysis radicals are formed by the above reactions, and these can interact with both the DTZ and $\mathrm{AC}$ in the medium, also giving rise to radical recombination reactions (Reactions $15-18)^{43}$.

$$
\begin{aligned}
& \mathrm{k}=7.0 \times 10^{9} \mathrm{M}^{-1} \mathrm{~s}^{-1} \\
& \mathrm{k}=7.8 \times 10^{9} \mathrm{M}^{-1} \mathrm{~s}^{-1} \\
& \mathrm{k}=2.5 \times 10^{10} \mathrm{M}^{-1} \mathrm{~s}^{-1} \\
& \mathrm{k}=3.0 \times 10^{10} \mathrm{M}^{-1} \mathrm{~s}^{-1}
\end{aligned}
$$

presence of $\mathrm{AC}$. The values obtained for $\mathrm{k}_{\mathrm{ob}}$ in the presence of anion $\mathrm{Cl}^{-}$, both for carbons $\mathrm{C}$ and $\mathrm{S}$, indicate the absence of a synergic effect under these experimental conditions (Table 4, experiments 2125 ), given that the radiolysis, $\mathrm{k}_{\mathrm{Rad}}$, and adsorption, $\mathrm{k}_{\mathrm{Ad}}$, values were higher than the $\mathrm{k}_{\mathrm{ob}}$ value. This behavior can be explained by the positive charge of the carbon surface at the study $\mathrm{pH}(\mathrm{pH}=1.0)$, because solution $\mathrm{pH}<\mathrm{pH}_{\mathrm{PZC}}$ (Table S2, supplementary data), whereas the DTZ has no charge (Figure 5). In this situation, the percentage DTZ adsorption is the lowest among the three experimental conditions studied, due to a possible screening of the carbon surface charge by the $\mathrm{Cl}^{-}$ions in the medium, reducing the interactions between the carbon surface and DTZ molecules. This mechanism would hamper the action of the AC in DTZ radiolysis. Furthermore, the $\mathrm{k}_{\text {Rad }}$ value is higher than the constants determined in experiments 26 and 31 (Table 4), indicating that 
radiolysis is favored under these conditions because of the elevated hydrogen reaction constant with DTZ $\left.(2.2 \pm 0.5) \times 10^{9} \mathrm{M}^{-1} \mathrm{~s}^{-1}\right)^{56}$.

Table 4. Influence of the presence of scavengers on DTZ removal. [DTZ $]_{0}=1000 \mathrm{mg} \mathrm{L}^{-1}$. $\mathrm{P}_{\mathrm{CA}}=0.06 \mathrm{~g}$ de CA. $\left[\mathrm{Cl}^{-}\right]=1000 \mathrm{mg} \mathrm{L}^{-1}$, Exp.: 21-25. [B r $\left.{ }^{-}\right]=1000 \mathrm{mg} \mathrm{L}^{-1}$, Exp.: 26-30. [ $\left.\mathrm{NO}_{3}{ }^{-}\right]=1000 \mathrm{mg} \mathrm{L}^{-1}$, Exp. 31-35. Dose Rate $=1.66 \mathrm{~Gy}^{-1}$. T $=298 \mathrm{~K}$.

\begin{tabular}{|c|c|c|c|c|c|c|c|}
\hline $\begin{array}{l}\mathrm{N}^{\circ} \text {. } \\
\text { Exp. }\end{array}$ & $\mathbf{C A}$ & $\mathbf{p H}$ & Radical & $\begin{array}{c}\% \text { DTZ } \\
\text { Removal }\end{array}$ & $\begin{array}{c}\mathbf{k}_{\mathbf{R a d}} \times \mathbf{1 0} \mathbf{1}^{\mathbf{4}} \\
\left(\mathrm{Gy}^{-1}\right)\end{array}$ & $\begin{array}{c}\mathbf{k}_{\mathrm{Ad}} \times \mathbf{1 0} \mathbf{0}^{\mathbf{4}} \\
\left(\mathrm{Gy}^{-1}\right)\end{array}$ & $\begin{array}{c}\mathbf{k}_{\mathbf{o b}} \times \mathbf{1 0}^{\mathbf{4}} \\
\left(\mathrm{Gy}^{-1}\right)\end{array}$ \\
\hline 21 & - & 1.0 & $\mathrm{H}^{\bullet}$ & 25.87 & $4.8 \pm 0.2$ & - & - \\
\hline 22 & $\mathrm{C}$ & 1.0 & $\mathrm{H}^{\bullet}$ & 20.32 & - & $3.45 \pm 0.05$ & - \\
\hline 23 & $\mathrm{C}$ & 1.0 & $\mathrm{H}^{\bullet}$ & 35.61 & - & - & $3.9 \pm 0.4$ \\
\hline 24 & S & 1.0 & $\mathrm{H}^{\bullet}$ & 20.67 & - & $3.1 \pm 0.3$ & - \\
\hline 25 & S & 1.0 & $\mathrm{H}^{\bullet}$ & 35.97 & - & - & $2.61 \pm 0.08$ \\
\hline 26 & - & 7.5 & $\overline{\mathrm{e}_{\mathrm{aq}}^{-}}$ & 11.55 & $1.15 \pm 0.03$ & - & - \\
\hline 27 & $\mathrm{C}$ & 7.5 & $e_{a q}^{-}$ & 23.93 & - & $4.1 \pm 0.2$ & \\
\hline 28 & $\mathrm{C}$ & 7.5 & $e_{a q}^{-}$ & 37.27 & - & - & $7.0 \pm 0.2$ \\
\hline 29 & S & 7.5 & $\mathrm{e}_{\mathrm{aq}}^{-}$ & 33.16 & - & $6.1 \pm 0.3$ & \\
\hline 30 & S & 7.5 & $\mathrm{e}_{\mathrm{aq}}^{-}$ & 49.25 & - & - & $9.7 \pm 0.2$ \\
\hline 31 & - & 12.5 & $\mathrm{OH}^{\bullet}$ & 8.51 & $0.87 \pm 0.03$ & - & - \\
\hline 32 & $\mathrm{C}$ & 12.5 & $\mathrm{OH}^{\bullet}$ & 16.13 & - & $2.94 \pm 0.07$ & - \\
\hline 33 & $\mathrm{C}$ & 12.5 & $\mathrm{OH}^{\bullet}$ & 24.28 & - & - & $4.1 \pm 0.3$ \\
\hline 34 & S & 12.5 & $\mathrm{OH}^{\bullet}$ & 26.56 & - & $3.76 \pm 0.08$ & - \\
\hline 35 & $S$ & 12.5 & $\mathrm{OH}^{\bullet}$ & 32.46 & - & - & $5.1 \pm 0.4$ \\
\hline
\end{tabular}

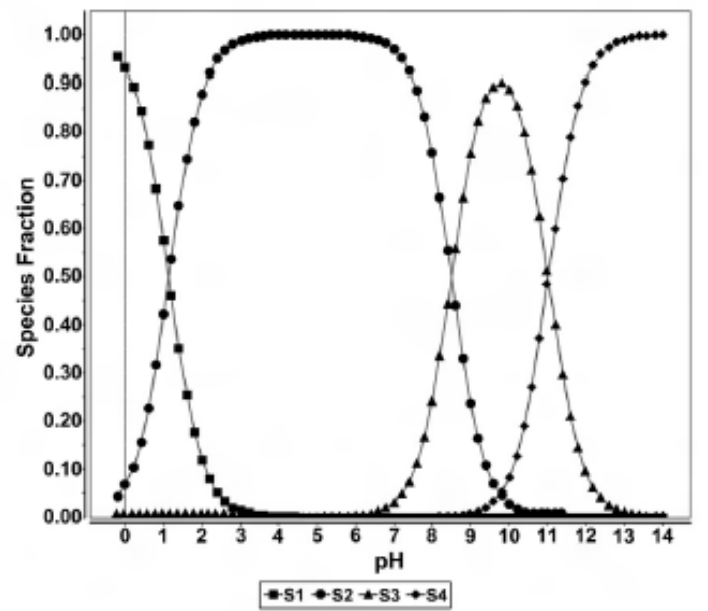<smiles>CC(=O)Nc1c(I)c(NC(C)=O)c(I)c(C(=O)O)c1I</smiles><smiles>CC(=O)Nc1c(I)c(NC(C)=O)c(I)c(C(=O)O)c1I</smiles><smiles>COC(=O)c1c(I)c(NC(C)=O)c(I)c(NC(C)=O)c1I</smiles><smiles>CC(=O)Nc1c(I)c(NC(C)=O)c(I)c(C(=O)O)c1I</smiles>

S4

Figure 5. Molecular structure of DTZ and its species distribution as a function of solution pH.

In addition, the $\mathrm{k}_{\mathrm{ob}}$ value is lower than the $\mathrm{k}_{\mathrm{Rad}}$ value, suggesting that some of the $\mathrm{H}^{\bullet}$ radicals formed during radiolysis interact with the $\mathrm{AC}$ present in the medium, forming highly reactive centers, stabilized by delocalization over the large conjugated aromatic rings system (Figure 6$)^{55}$. The reactive centers formed would not react with DTZ because this compound cannot gain access to the carbon surface, as a result the action of chloride anions.

According to the results in Table 4 , the $\mathrm{k}_{\mathrm{ob}}$ value was highest when solvated electrons were the predominant species. In addition, the DTZ removal by radiolysis in the presence of $\mathrm{AC}$ was the highest among the three experimental conditions considered, being $49.25 \%$ for carbon $\mathrm{S}$ and $37.27 \%$ for carbon $\mathrm{C}$. The contribution of adsorption to DTZ removal was only $23.93 \%$ for carbon $\mathrm{C}$ and $33.16 \%$ for carbon $\mathrm{S}$, with $\mathrm{k}_{\mathrm{ad}}$ values of $(4.1 \pm 0.2) \times 10^{-4} \mathrm{~Gy}^{-1}$ and $(6.1 \pm$ $0.3) \times 10^{-4} \mathrm{~Gy}^{-1}$, respectively. This difference is attributable to their different $\mathrm{pH}_{\mathrm{PZC}}$ values, given that the surface of carbon $\mathrm{C}$ has no charge at the study $\mathrm{pH}$ $(\mathrm{pH}=7.5)$, due to its proximity to the $\mathrm{pH}_{\mathrm{PZC}}$ value, 
whereas carbon $\mathrm{S}$ has a net positive charge and favors attractive electrostatic interactions between adsorbate and adsorbent, because DTZ has a negative charge at this $\mathrm{pH}$ (Figure 5). The $\mathrm{k}_{\mathrm{SE}}$ values calculated for the two carbons is $(1.7 \pm 0.5) \times 10^{-4} \mathrm{~Gy}^{-1}$ for carbon $\mathrm{C}$ and
$(2.4 \pm 0.5) \times 10^{-4} \mathrm{~Gy}^{-1}$ for carbon S. This difference may be attributable to the higher quinone groups content of carbon $\mathrm{S}$, which can stabilize radicals on its surface, forming highly reactive centers that can degrade DTZ (Figure 7).

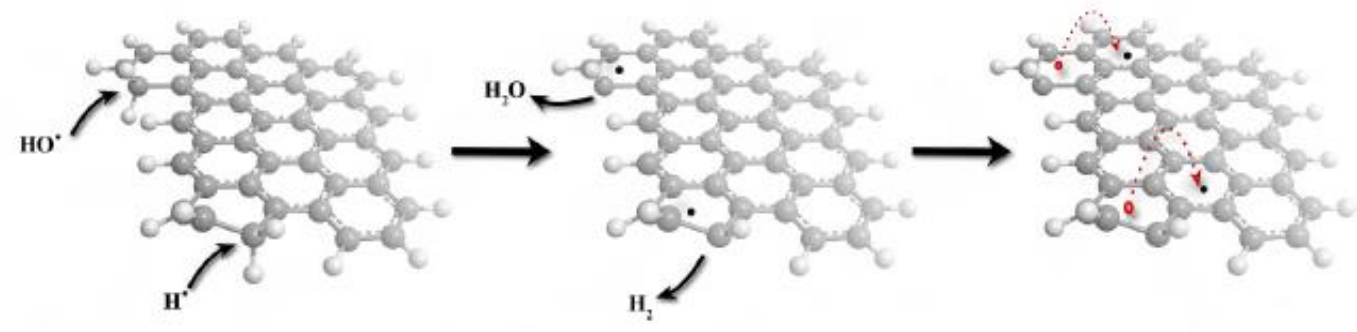

Figure 6. Stabilization of radicals by delocalization over conjugated aromatic rings system.

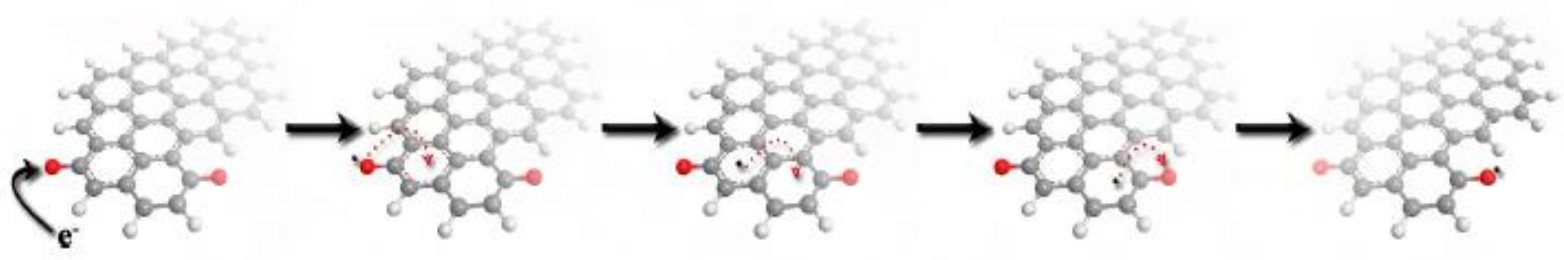

Figure 7. Stabilization of by delocalization radicals over quinone groups.

Finally, the experiments conducted in the presence of the hydroxyl radical (Table 4, experiments 31-35) showed that: (i) radiolysis is reduced in the absence of AC, degrading only $8.51 \%$ of initial concentration of DTZ and obtaining the lowest $\mathrm{k}_{\mathrm{Rad}}$ value among the three experimental conditions, because the DTZ degradation reaction rate constant with the hydroxyl radical $\left[\mathrm{K}_{\mathrm{OH}}\right.$ (DTZ) $=(5.4$ $\left.\pm 0.3) \times 10^{8} \mathrm{M}^{-1} \mathrm{~s}^{-1}\right]$ is the lowest among the three species studied; (ii) the contribution of the adsorption process is lower, because both carbon $\mathrm{C}$ and $\mathrm{S}$ have a negative surface charge $\left(\mathrm{pH}_{\text {medium }}>\mathrm{pH} \mathrm{PZC}_{\mathrm{PC}}\right)$, producing repulsive electrostatic interactions between adsorbent and adsorbate, given that DTZ is negatively charged at this $\mathrm{pH}$ (Figure 5). Hence, there is a predominance of dispersive interactions between the $\pi$ electrons of the DTZ aromatic ring and the $\pi$ electrons of the graphene planes of the $\mathrm{AC}$ ( $\pi-\pi$ interactions) in this adsorption system, as proposed by Coughlin et al. ${ }^{57}$; and (iii) the $\mathrm{k}_{\mathrm{SE}}$ value is $(2.9 \pm 0.5) \times 10^{-5} \mathrm{~Gy}^{-1}$ for carbon $\mathrm{C}$ and $(4.7 \pm 0.5) \times 10^{-5} \mathrm{~Gy}^{-1}$ for carbon $\mathrm{S}$, an order of magnitude lower than the value determined in the presence of solvated electrons; furthermore, as in the case of $\mathrm{H}^{\bullet}$ radicals, the hydroxyl radical interacts with the AC present, which competes with the DTZ for this radical (Table 4, experiments 21-25).

Therefore, the results obtained in the presence of anions indicate that there must be a first step of electrostatic interactions between the DTZ molecules and AC surface for the synergic effect to take place. When the surface charge of the carbon hinders or impedes these interactions or when the presence of ions screen the adsorbate-adsorbent interactions, the synergic effect is reduced or even disappears.

\section{Conclusion}

The different advanced oxidation/reduction processes that have been studied shown positive results in the DTZ degradation. They were improved through the addition of $\mathrm{AC}$ in the UV light and gamma radiating processes.

The results of this study demonstrate that the presence of activated carbon during the DTZ photodegradation process markedly increases the removal rate, regardless of the activated carbon used. The results obtained indicate that activated carbon $\mathrm{W}$ exerts the greatest synergic effect on DTZ removal by the UV/AC system, with a synergic contribution $>53 \%$ at one minute of treatment. Regardless of the activated carbon sample considered, its synergic activity is, in general, enhanced by the gamma radiation treatment.

The textural and chemical properties of the activated carbons used show no clear relationship with their synergic contribution. However, the synergic activity of the activated carbon is more greatly enhanced by the samples with higher percentages of surface oxygen and, among these, the samples with higher percentages of carbon atoms with $\mathrm{sp}^{2}$ hybridization. Determination of the activated carbon band gap demonstrated that these materials behave as semiconductor materials and therefore as photoactive materials in the presence of UV radiation, because all $\mathrm{E}_{\mathrm{g}}$ values are $<4 \mathrm{eV}$.

In general, the gamma radiation treatment of activated carbons reduce the band gap energy of these materials and, within the same series of activated carbons, lower $\mathrm{E}_{\mathrm{g}}$ values correspond to higher $\mathrm{k}_{\mathrm{OB}}$ values. We indicate that the percentage of carbon atoms with $\mathrm{sp}^{2}$ hybridization is increased in the gamma irradiation modified materials, reducing their 
band gap, explaining their usually superior behavior in DTZ photodegradation.

Related to the mechanism involved in the radiolysis/AC process used, the results obtained show that the solvated electrons formed during water radiolysis may interact with the AC surface, giving rise to areas with high reactivity due to the stabilization of the radicals by the quinone groups on the surface. The influence of this mechanism would be greater with higher quinone content. Moreover, analysis of the role in DTZ removal of the radical species produced by water radiolysis shows that adsorbate-adsorbent electrostatic interactions are necessary to obtain a synergic effect on pollutant degradation.

Based on these results, an action mechanism for the removal of DTZ in the presence of activated carbon is proposed, in which the activated carbon can act as a photocatalyst, in presence of ultraviolet radiation, promoting electrons of the valence band to the conduction band and increasing the generation of $\mathrm{OH}^{\bullet}$ radicals in the medium. Moreover, activated carbon can stabilize radicals formed on its surface, increasing the concentration of radicals, which improves the contaminant elimination process.

\section{Acknowledgements}

The authors are grateful for the financial support provided by the Junta de Andalucía (RNM7522) and the Spanish Ministry of Science and Innovation (CTQ2011-29035-C02-02).

\section{References}

1- J. M. Dias, M. C. M. Alvim-Ferraz, M. F. Almeida, J. Rivera-Utrilla and M. Sánchez-Polo, J. Environ. Manage., 2007, 85, 833-846.

2- K. Y. Foo and B. H. Hameed, J. Hazard. Mater., 2010, 175, 1-11.

3- C. Gabaldón, P. Marzal, A. Seco and J. A. Gonzalez, Sep. Sci. Technol., 2000, 35, 1039-1053.

4- K. Urano, E. Yamamoto, M. Tonegawa and K. Fujie, Water Res., 1991, 25, 1459-1464.

5- C. Moreno-Castilla and J. Rivera-Utrilla, MRS Bull., 2001, 26, 890-894.

6- F. Blanco, X. Vilanova, V. Fierro, A. Celzard, P. Ivanov, E. Llobet, N. Cañellas, J. L. Ramírez and X. Correig, Sens. Actuators, B, 2008, 132, 90-98.

7- D. Montané, D. Nabarlatz, A. Martorell, V. Torné-Fernández and V. Fierro, Ind. Eng. Chem. Res., 2006, 45, 2294-2302.

8- K. Okada, N. Yamamoto, Y. Kameshima and A. Yasumori, J. Colloid Interface Sci., 2003, 262, 194-199.

9- J. Rivera-Utrilla, M. Sánchez-Polo, V. GómezSerrano, P. M. Álvarez, M. C. M. Alvim-Ferraz and J. M. Dias, J. Hazard. Mater., 2011, 187, 123.
10- X. Li, Q. Zhang, L. Tang, P. Lu, F. Sun and L. Li, J. Hazard. Mater., 2009, 163, 115-120.

11- T. Merle, J. S. Pic, M. H. Manero, S. Mathé and H. Debellefontaine, Catal. Today, 2010, 151, 166-172.

12- J. Rivera-Utrilla and M. Sánchez-Polo, Appl. Catal., B, 2002, 39, 319-329.

13- M. Sánchez-Polo and J. Rivera-Utrilla, Carbon, 2003, 41, 303-307.

14- Y.-Z. Zhang, X.-Y. Xiong, Y. Han and W. Zhou, Proc. Environ. Sci., 2011, 11, Part B, 668-673.

15- M. H. Baek, W. C. Jung, J. W. Yoon, J. S. Hong, Y. S. Lee and J. K. Suh, J. Ind. Eng. Chem., 2013, 19, 469-477.

16- H. Choi, E. Stathatos and D. D. Dionysiou, Appl. Catal., B, 2006, 63, 60-67.

17- T. Cordero, C. Duchamp, J. M. Chovelon, C. Ferronato and J. Matos, J. Photochem. Photobiol., A, 2007, 191, 122-131.

18- G. Li Puma, A. Bono, D. Krishnaiah and J. G. Collin, J. Hazard. Mater., 2008, 157, 209-219.

19- T. T. Lim, P. S. Yap, M. Srinivasan and A. G. Fane, Crit. Rev. Env. Sci. Technol., 2011, 41, 1173-1230.

20- J. Matos, A. Garcia, T. Cordero, J. M. Chovelon and C. Ferronato, Catal. Lett., 2009, 130, 568574.

21- J. Rivera-Utrilla, M. Sánchez-Polo, M. M. Abdel Daiem and R. Ocampo-Pérez, Appl. Catal., B, 2012, 126, 100-107.

22- J. L. Figueiredo and M. F. R. Pereira, Catal. Today, 2010, 150, 2-7.

23- F. Rodríguez-reinoso, Carbon, 1998, 36, 159-175

24- W. Wang, C. G. Silva and J. L. Faria, Appl. Catal., B, 2007, 70, 470-478.

25- I. Velo-Gala, J. J. López-Peñalver, M. SánchezPolo and J. Rivera-Utrilla, Appl. Catal., B, 2013, 142-143, 694-704.

26- I. A. E. A. IAEA. Status of industrial scale radiation treatment of wastewater and its future. (2004).

27- I. A. E. A. IAEA. Nuclear technology review. (2004).

28- I. A. E. A. IAEA. Radiation Processing: Environmental Applications. (2007).

29- I. A. E. A. IAEA. Radiation treatment of polluted water and wastewater. (2008).

30- M. Carballa, F. Omil, J. M. Lema, M. a. Llompart, C. García-Jares, I. Rodríguez, M. Gómez and T. Ternes, Water Res., 2004, 38, 2918-2926.

31- J. E. Drewes, P. Fox and M. Jekel, J. Environ. Sci. Health, Part A: Toxic/Hazard. Subst. Environ. Eng., 2001, 36, 1633-1645.

32- L. J. Fono, E. P. Kolodziej and D. L. Sedlak, Environ. Sci. Technol., 2006, 40, 7257-7262.

33- A. Putschew, S. Wischnack and M. Jekel, Sci. Total Environ., 2000, 255, 129-134.

34- T. Ternes, Prepr. Ext. Abstr. ACS Natl. Meet., Am. Chem. Soc., Div., 2000, 40, 98-100. 
35- T. Heberer, Toxicol. Lett., 2002, 131, 5-17.

36- W. Kalsch, Sci. Total Environ., 1999, 225, 143 153.

37- A. Haiß and K. Kümmerer, Chemosphere, 2006, 62, 294-302.

38- S. Pérez and D. Barceló, Anal. Bioanal. Chem., 2007, 387, 1235-1246.

39- M. M. Huber, A. Göbel, A. Joss, N. Hermann, D. Löffler, C. S. McArdell, A. Ried, H. Siegrist, T. A. Ternes and U. Von Gunten, Environ. Sci. Technol., 2005, 39, 4290-4299.

40- T. A. Ternes, J. Stüber, N. Herrmann, D. McDowell, A. Ried, M. Kampmann and B. Teiser, Water Res., 2003, 37, 1976-1982.

41- I. Velo-Gala, J. J. López-Peñalver, M. SánchezPolo and J. Rivera-Utrilla, Carbon, 2014, 67, 236-249.

42- E. Atinault, V. De Waele, U. Schmidhammer, M. Fattahi and M. Mostafavi, Chem. Phys. Lett., 2008, 460, 461-465.

43- G. V. Buxton, C. L. Greenstock, W. P. Helman and A. B. Ross, J. Phys. Chem. Ref. Data, 1988, 17, 2593-2600.

44- B. G. Ershov, M. Kelm, A. V. Gordeevb and E. Janata, Phys. Chem. Chem. Phys., 2002, 4, 1872-1875.

45- J. A. LaVerne, M. R. Ryan and T. Mu, Radiat. Phys. Chem., 2009, 78, 1148-1152.
46- O. Roth and J. A. Laverne, J. Phys. Chem. A, 2011, 115, 700-708.

47- S. P. Mezyk and D. M. Bartels, J. Phys. Chem. A, 1997, 101, 6233-6237.

48- G. Fanchini, S. C. Ray and A. Tagliaferro, Surface and Coatings Technology, 2002, 151-152, 233-241.

49- H. P. Boehm, Carbon, 2012, 50, 3154-3157.

50- B. Campbell and A. Mainwood, Phys. Status Solidi A, 2000, 181, 99-107.

51- B. G. Ershov and A. V. Gordeev, Radiat. Phys. Chem., 2008, 77, 928-935.

52- J. M. Joseph, B. Seon Choi, P. Yakabuskie and J. Clara Wren, Radiat. Phys. Chem., 2008, 77, 1009-1020.

53- R. Laenen, T. Roth and A. Laubereau, Phys. Rev. Lett., 2000, 85, 50-53.

54- D. Swiatla-Wojcik and G. V. Buxton, J. Chem. Soc., Faraday Trans., 1998, 94, 2135-2141.

55- E. A. Voudrias, R. A. Larson and V. L. Snoeyink, Carbon, 1987, 25, 503-515.

56- I. Velo-Gala, J. J. López-Peñalver, M. SánchezPolo and J. Rivera-Utrilla, Chem. Eng. J., 2012, 195-196, 369-376.

57- R. W. Coughlin and F. S. Ezra, Environ. Sci. Technol., 1968, 2, 291-297. 


\title{
Role of activated carbon on micropollutans degradation by different radiation processes
}

\author{
Inmaculada Velo-Gala, Jesús J. López-Peñalver*, Manuel Sánchez-Polo, José Rivera-Utrilla
}

Department of Inorganic Chemistry, Faculty of Science, Granada University, Granada, Spain

Table S1. Effect of gamma irradiation on the textural characteristics of ACs.

\begin{tabular}{llllllll}
\hline ACs & $\begin{array}{l}\mathrm{S}_{\mathrm{BET}^{\mathrm{a}}}\left(\mathrm{N}_{2}\right) \\
\left(\mathrm{m}^{2} \mathrm{~g}^{-1}\right)\end{array}$ & $\begin{array}{l}\mathrm{V}_{\mathrm{T}}^{\mathrm{b}}\left(\mathrm{N}_{2}\right) \\
\left(\mathrm{cm}^{3} \mathrm{~g}^{-1}\right)\end{array}$ & $\begin{array}{l}\mathrm{D}_{\mathrm{P}}^{\mathrm{c}}\left(\mathrm{N}_{2}\right) \\
(\mathrm{nm})\end{array}$ & $\begin{array}{l}\mathrm{V}_{0}{ }^{\mathrm{d}}\left(\mathrm{N}_{2}\right) \\
\left(\mathrm{cm}^{3} \mathrm{~g}^{-1}\right)\end{array}$ & $\begin{array}{l}\mathrm{S}_{\mathrm{Ext}}{ }^{\mathrm{e}}\left(\mathrm{N}_{2}\right) \\
(\mathrm{nm})\end{array}$ & $\begin{array}{l}\mathrm{V}_{0}{ }^{\mathrm{f}}\left(\mathrm{CO}_{2}\right) \\
\left(\mathrm{cm}^{3} \mathrm{~g}^{-1}\right)\end{array}$ & $\mathrm{V}_{0}\left(\mathrm{~N}_{2}\right) / \mathrm{V}_{0}\left(\mathrm{CO}_{2}\right)$ \\
\hline $\mathrm{W}$ & 815 & 0.40 & 1.97 & 0.35 & 20.39 & 0.26 & 1.36 \\
$\mathrm{~W}-\mathrm{A}$ & 798 & 0.39 & 1.97 & 0.35 & 23.06 & 0.25 & 1.40 \\
$\mathrm{~W}-0$ & 794 & 0.39 & 1.97 & 0.35 & 20.14 & 0.24 & 1.43 \\
$\mathrm{C}$ & 1294 & 0.65 & 2.02 & 0.55 & 82.68 & 0.34 & 1.60 \\
$\mathrm{C}-\mathrm{A}$ & 1256 & 0.64 & 2.03 & 0.54 & 71.97 & 0.33 & 1.65 \\
$\mathrm{C}-0$ & 1248 & 0.63 & 2.04 & 0.53 & 73.78 & 0.33 & 1.62 \\
$\mathrm{M}$ & 1302 & 0.66 & 2.02 & 0.55 & 84.00 & 0.39 & 1.41 \\
$\mathrm{M}-\mathrm{A}$ & 1286 & 0.64 & 1.99 & 0.54 & 75.54 & 0.38 & 1.43 \\
$\mathrm{M}-0$ & 1278 & 0.63 & 1.97 & 0.54 & 71.16 & 0.38 & 1.44 \\
$\mathrm{~S}$ & 1143 & 0.57 & 2.02 & 0.49 & 53.84 & 0.29 & 1.68 \\
$\mathrm{~S}-\mathrm{A}$ & 1049 & 0.52 & 2.00 & 0.45 & 47.48 & 0.27 & 1.67 \\
$\mathrm{~S}-0$ & 1031 & 0.52 & 2.03 & 0.44 & 53.22 & 0.28 & 1.66 \\
\hline
\end{tabular}

a Surface area determined from $\mathrm{N}_{2}$ adsorption isotherms at $77 \mathrm{~K}$.

b Total pore volume calculated for $\mathrm{P} / \mathrm{P}_{0}=0.99$.

${ }^{\mathrm{c}}$ Mean pore width determined for a cylindrical model.

${ }^{\mathrm{d}}$ Micropore volume determined by the $\mathrm{t}$ method.

e External surface area calculated by the t method.

${ }^{\mathrm{f}}$ Ultramicropore volume based on $\mathrm{CO}_{2}$ adsorption isotherms at $273 \mathrm{~K}$ following Dubinin-Radushkevich equation. 
Table S2. Effect of gamma irradiation on the chemical properties of the ACs.

\begin{tabular}{|c|c|c|c|}
\hline ACs & pHPZC & $\begin{array}{l}\text { Acidic groups }{ }^{\mathrm{a})} \\
\left(\mu \mathrm{eq} \mathbf{g}^{-1}\right)\end{array}$ & $\begin{array}{l}\text { Basic groups }{ }^{\text {b) }} \\
\left(\mu \mathrm{eq} \mathrm{g}^{-1}\right)\end{array}$ \\
\hline $\mathbf{W}$ & $8.4 \pm 0.2$ & 188 & 403 \\
\hline W-A & $9.2 \pm 0.2$ & 88 & 622 \\
\hline W-o & $7.1 \pm 0.1$ & 128 & 340 \\
\hline W-Hי & $4.7 \pm 0.1$ & 448 & 186 \\
\hline$W-e^{-} a q$ & $9.1 \pm 0.2$ & 100 & 558 \\
\hline W-HO & $9.6 \pm 0.1$ & 50 & 688 \\
\hline C & $7.5 \pm 0.2$ & 240 & 409 \\
\hline C-A & $8.7 \pm 0.2$ & 107 & 657 \\
\hline $\mathrm{C}-\mathrm{O}$ & $7.7 \pm 0.2$ & 246 & 462 \\
\hline $\mathrm{C}-\mathrm{H}^{\bullet}$ & $3.1 \pm 0.2$ & 488 & 158 \\
\hline $\mathrm{C}-\mathrm{e}^{-} \mathrm{aq}^{-}$ & $7.2 \pm 0.2$ & 166 & 467 \\
\hline C-HO & $7.7 \pm 0.2$ & 226 & 500 \\
\hline $\mathbf{M}$ & $10.0 \pm 0.2$ & 72 & 650 \\
\hline M-A & $10.7 \pm 0.2$ & 90 & 736 \\
\hline M-0 & $9.3 \pm 0.1$ & 105 & 468 \\
\hline M-H' & $4.2 \pm 0.2$ & 453 & 150 \\
\hline M-e-aq & $8.4 \pm 0.2$ & 68 & 389 \\
\hline M-HO• & $9.0 \pm 0.2$ & 48 & 431 \\
\hline
\end{tabular}

a Determined by neutralization with $\mathrm{NaOH}(0.05 \mathrm{~N})$.

b Determined by neutralization with $\mathrm{HCl}(0.05 \mathrm{~N})$. 


\section{Available free online at www.medjchem.com \\ Supplementary data \\ Mediterranean Journal of Chemistry 2015, 4(2), 68-80}

Table S3. Atomic percentages of carbon $(\mathrm{C} 1 \mathrm{~s})$ and oxygen $(\mathrm{O} 1 \mathrm{~s})$ surface obtained by XPS analysis of pristine and modified activated carbon.

\section{C1s}

\begin{tabular}{|c|c|c|c|c|c|c|}
\hline $\begin{array}{c}\text { Type of } \\
\text { AC } \\
\end{array}$ & $\mathrm{AC}$ a) & $A C-A^{b)}$ & $\mathrm{AC}-0^{\mathrm{c}}{ }^{\mathrm{s}}$ & $\left.\mathbf{A C}-\mathrm{H}^{\bullet} \mathbf{d}\right)$ & $A C-e^{-}{ }^{e}{ }^{e}$ & AC-HO ${ }^{\bullet}$ f \\
\hline $\mathbf{W}$ & 95.36 & 94.90 & 93.32 & 94.10 & 93.52 & 92.22 \\
\hline $\mathbf{C}$ & 95.04 & 92.92 & 88.01 & 95.91 & 94.42 & 82.55 \\
\hline $\mathbf{M}$ & 95.34 & 94.26 & 94.57 & 92.01 & 93.76 & 93.96 \\
\hline $\mathbf{S}$ & 95.69 & 92.97 & 79.94 & 95.79 & 86.13 & 75.88 \\
\hline \multicolumn{7}{|c|}{ O1s } \\
\hline $\begin{array}{c}\text { Type of } \\
\text { AC }\end{array}$ & $\mathrm{AC}^{\text {a) }}$ & $A C-A^{b)}$ & $\mathrm{AC}-\mathbf{0}^{\mathrm{c}} \mathrm{c}^{-}$ & $\left.\mathbf{A C}-\mathbf{H}^{\bullet} \mathbf{d}\right)$ & AC-e $\left.e_{a q}^{-a}\right)$ & $\mathrm{AC}-\mathrm{HO}^{\bullet}{ }^{\mathrm{f}}$ \\
\hline $\mathbf{W}$ & 3.42 & 3.90 & 5.48 & 4.87 & 5.46 & 6.78 \\
\hline $\mathbf{C}$ & 3.29 & 4.62 & 8.05 & 3.03 & 4.13 & 11.18 \\
\hline $\mathbf{M}$ & 4.14 & 5.16 & 4.63 & 7.11 & 5.35 & 5.14 \\
\hline $\mathbf{S}$ & 4.31 & 6.55 & 17.73 & 3.7 & 13.87 & 21.09 \\
\hline
\end{tabular}

\footnotetext{
a) Pristine activated carbon.

b) AC irradiated in the absence of water.

c) AC irradiated in ultrapure water.

d) $\mathrm{AC}$ irradiated in ultrapure water, $\mathrm{pH}=1.0$ and $\left[\mathrm{Cl}^{-}\right]=1000 \mathrm{mg} \mathrm{L}^{-1}$.

e) $\mathrm{AC}$ irradiated in ultrapure water, $\mathrm{pH}=7.5$ and $\left[\mathrm{Br}^{-}\right]=1000 \mathrm{mg} \mathrm{L}^{-1}$.

f) $\mathrm{AC}$ irradiated in ultrapure water, $\mathrm{pH}=12.5$ and $\left[\mathrm{NO}_{3}{ }^{-}\right]=1000 \mathrm{mg} \mathrm{L}^{-1}$.
} 
Table S4. XPS Results: deconvoluted C1s peaks of the XPS spectra for pristine and irradiated carbons.

\begin{tabular}{|c|c|c|c|c|c|c|c|}
\hline \multicolumn{8}{|c|}{ Peaks $^{\text {a) }}($ at $\%)$} \\
\hline & 1 & 2 & 3 & 4 & 5 & 6 & 7 \\
\hline $\mathbf{W}$ & 30.71 & 36.88 & 11.83 & 8.38 & 4.47 & 4.67 & 3.06 \\
\hline W-A & 50.30 & 18.81 & 11.88 & 6.65 & 3.76 & 5.04 & 3.57 \\
\hline W-0 & 45.62 & 19.98 & 16.54 & 6.57 & 3.87 & 3.91 & 3.52 \\
\hline W-H• & 53.57 & 16.29 & 13.84 & 5.92 & 3.91 & 3.48 & 2.99 \\
\hline $\mathbf{W}-\mathbf{e}^{-} \mathbf{a q}$ & 56.57 & 8.20 & 17.39 & 6.14 & 4.15 & 4.56 & 3.99 \\
\hline W-HO• & 50.29 & 13.99 & 18.75 & 5.94 & 4.48 & 3.37 & 3.19 \\
\hline $\mathbf{C}$ & 33.03 & 30.32 & 18.14 & 6.99 & 4.93 & 4.82 & 1.78 \\
\hline C-A & 36.94 & 26.09 & 17.46 & 6.43 & 3.98 & 5.33 & 3.78 \\
\hline C-0 & 36.19 & 27.62 & 16.49 & 6.67 & 4.49 & 5.01 & 3.54 \\
\hline C-H• & 39.68 & 26.10 & 16.97 & 6.20 & 4.37 & 4.76 & 1.92 \\
\hline$C-e^{-}$ & 38.13 & 27.67 & 16.66 & 6.69 & 4.29 & 4.67 & 1.89 \\
\hline C-HO' & 35.49 & 28.50 & 17.57 & 6.92 & 5.21 & 4.70 & 1.90 \\
\hline M & 22.97 & 35.22 & 21.56 & 7.95 & 3.32 & 6.67 & 2.30 \\
\hline M-A & 51.50 & 13.64 & 12.63 & 9.15 & 4.10 & 5.00 & 3.98 \\
\hline M-0 & 51.25 & 15.14 & 12.12 & 9.36 & 3.85 & 4.54 & 3.73 \\
\hline M-H & 38.04 & 9.79 & 29.84 & 10.22 & 3.94 & 5.37 & 2.80 \\
\hline$M-e^{-}=$ & 40.73 & 16.43 & 21.84 & 8.94 & 3.70 & 5.87 & 2.50 \\
\hline M-HO• & 44.36 & 13.01 & 22.32 & 8.50 & 3.55 & 5.79 & 2.46 \\
\hline $\mathbf{S}$ & 26.73 & 34.62 & 14.18 & 8.97 & 5.97 & 4.53 & 5.00 \\
\hline S-A & 42.63 & 20.17 & 14.12 & 8.29 & 5.23 & 4.47 & 5.10 \\
\hline S-0 & 46.81 & 18.28 & 14.78 & 7.33 & 4.59 & 4.74 & 3.47 \\
\hline S-H• & 36.12 & 18.26 & 28.95 & 8.18 & 4.08 & 2.42 & 1.90 \\
\hline$S-e^{-}$ & 35.16 & 17.19 & 24.71 & 13.09 & 5.62 & 2.82 & 1.41 \\
\hline S-HO & 38.60 & 20.58 & 18.33 & 12.42 & 5.38 & 3.75 & 0.94 \\
\hline
\end{tabular}

a) Spectrum calibrated by reference to $\mathrm{C} 1 \mathrm{~s}(284.5 \mathrm{eV}) . \%$ is percentage of total area. Peaks: $1, \mathrm{C}-\mathrm{C}$ bond with $\mathrm{sp}^{2}$ hybridization; 2, $\mathrm{C}-\mathrm{C}$ bond of the graphene planes with $\mathrm{sp}^{3}$ hybridization, $\mathrm{C}-\mathrm{H} ; 3, \mathrm{C}-\mathrm{O}$ simple bond (alcohol, ether, phenol, and keto-enol); 4, $\mathrm{C}=\mathrm{O}$ double bond (carbonyl, quinones, and ketones); 5, $\mathrm{O}-\mathrm{C}=\mathrm{O}$ bond in carboxylic acids and anhydrides; $6, \pi-\pi^{*}$ transitions; 7 , Plasmon.

Table S5. XPS Results: deconvoluted O1s peaks of the XPS spectra for pristine and irradiated carbons. 


\begin{tabular}{|c|c|c|c|c|c|c|c|}
\hline \multicolumn{8}{|c|}{ Peaks ${ }^{\text {a) }}$ (at \%) } \\
\hline & 1 & 2 & 3 & 4 & 5 & 6 & 7 \\
\hline $\mathbf{W}$ & 31.95 & 21.27 & 24.36 & 11.15 & 6.07 & 2.69 & 2.52 \\
\hline W-A & 25.93 & 21.97 & 24.36 & 14.69 & 6.19 & 4.10 & 2.76 \\
\hline W-0 & 31.05 & 21.50 & 21.28 & 14.51 & 6.07 & 2.95 & 2.63 \\
\hline $\mathbf{W}-\mathbf{H}^{\bullet}$ & 32.93 & 23.68 & 21.91 & 11.11 & 4.50 & 2.84 & 3.03 \\
\hline $\mathbf{W}-\mathbf{e}^{-} \mathbf{a q}^{-}$ & 31.24 & 20.20 & 21.16 & 14.77 & 5.69 & 2.69 & 4.24 \\
\hline W-HO & 33.18 & 25.42 & 10.35 & 21.93 & 5.97 & 2.23 & 0.92 \\
\hline $\mathbf{C}$ & 21.64 & 22.27 & 23.54 & 15.18 & 12.69 & 1.62 & 3.03 \\
\hline C-A & 24.25 & 23.00 & 22.00 & 14.48 & 11.43 & 1.99 & 2.84 \\
\hline $\mathrm{C}-\mathrm{O}$ & 28.92 & 25.31 & 20.46 & 14.13 & 7.64 & 1.84 & 1.70 \\
\hline $\mathrm{C}-\mathrm{H}^{\bullet}$ & 26.32 & 21.78 & 19.75 & 18.21 & 5.63 & 4.25 & 4.07 \\
\hline$C-e^{-} a q$ & 22.15 & 23.66 & 17.52 & 20.55 & 7.55 & 4.29 & 4.29 \\
\hline C-HO• & 9.6 & 16.52 & 21.41 & 19.62 & 18.40 & 10.79 & 3.66 \\
\hline $\mathbf{M}$ & 22.63 & 22.02 & 15.50 & 22.63 & 9.05 & 4.21 & 3.96 \\
\hline M-A & 25.63 & 34.17 & 15.11 & 15.24 & 2.70 & 2.06 & 5.10 \\
\hline M-0 & 37.92 & 20.42 & 16.84 & 13.54 & 6.89 & 2.31 & 2.10 \\
\hline M-H• & 24.60 & 25.60 & 19.95 & 18.31 & 6.90 & 3.04 & 1.60 \\
\hline $\mathbf{M}-\mathbf{e}^{-} \mathbf{a q}$ & 22.44 & 20.81 & 21.89 & 17.56 & 9.91 & 2.92 & 4.46 \\
\hline M-HO & 24.04 & 20.10 & 18.57 & 21.97 & 7.81 & 4.87 & 2.64 \\
\hline $\mathbf{S}$ & 39.96 & 16.46 & 17.78 & 12.66 & 7.16 & 3.89 & 2.09 \\
\hline S-A & 18.69 & 26.83 & 23.36 & 12.80 & 11.77 & 3.24 & 3.31 \\
\hline S-0 & 34.93 & 32.31 & 18.52 & 10.03 & 2.96 & 1.16 & 0.09 \\
\hline S-H• & 22.33 & 19.54 & 24.92 & 19.58 & 6.59 & 4.41 & 2.63 \\
\hline S-e ${ }^{-}{ }^{-a q}$ & 11.80 & 29.25 & 17.96 & 24.55 & 12.40 & 3.40 & 0.64 \\
\hline S-HO & 8.56 & 29.37 & 22.83 & 23.74 & 11.08 & 3.29 & 1.14 \\
\hline
\end{tabular}

a) Percentage of total area. Peaks: $1, \mathrm{C}=\mathrm{O}$ in quinones, carbonyl groups; 2 , Oxygen of the carbonyl group $(\mathrm{C}=\mathrm{O})$ present in lactones, anhydrides, oxygen atom of hydroxyl groups $(-\mathrm{OH}) ; 3$, Oxygen atom in lactones and anhydrides (-C-O-C-); 4, Oxygen atom in carboxyl groups (- $\mathrm{COOH}$ or $\mathrm{COOR}) ; 5$, Water or chemisorbed oxygen; 6, Physisorbed water; 7, Plasmon. 
Table S6. Pearson's correlation coefficients for the relationship between $\mathrm{E}_{\mathrm{g}}$ value and $\mathrm{sp}^{3} / \mathrm{sp}^{2}$ ratio.

\begin{tabular}{|c|c|c|}
\hline & $\mathrm{sp}^{3} / \mathrm{sp}^{2}$ ratio & Eg \\
\hline $\mathrm{sp}^{3} / \mathrm{sp}^{2}$ ratio & & 0.5135 \\
\hline Sample Size & & (24) \\
\hline P-Value & & 0.0103 \\
\hline Eg & 0.5135 & \\
\hline Sample Size & (24) & \\
\hline P-Value & 0.0103 & \\
\hline
\end{tabular}

\section{Correlation}

(Sample Size)

P-value

This Table shows the Pearson product-moment correlations between the $\mathrm{E}_{\mathrm{g}}$ value and $\mathrm{sp}^{3} / \mathrm{sp}^{2}$ ratio. $\mathrm{P}$-value $<0.05$ was considered statistically significant at the $95.0 \%$ confidence level. 